\title{
QTL Mapping of Traits Associated with Dual Resistance to the African Stem Borer (Busseola fusca) and Spotted Stem Borer (Chilo partellus) in Sorghum (Sorghum bicolor)
}

\author{
Phyllis W. Muturi ${ }^{1},{ }^{1}$ Mary Mgonja, ${ }^{2}$ Patrick Rubaihayo, ${ }^{3}$ and James K. Mwololo ${ }^{4}$ \\ ${ }^{1}$ Department of Agricultural Resource Management, University of Embu, P.O. Box 60100, Embu, Kenya \\ ${ }^{2}$ Alliance for a Green Revolution in Africa, P.O. Box 34441, Dar es Salaam, Tanzania \\ ${ }^{3}$ Department of Agricultural Production, Makerere University, P.O. Box 7062, Kampala, Uganda \\ ${ }^{4}$ East and South African Research Program, International Crops Research Institute of the Semi-Arid Tropics (ICRISAT), \\ P.O. Box 1096 Lilongwe, Malawi
}

Correspondence should be addressed to Phyllis W. Muturi; muturi.phyllis@embuni.ac.ke

Received 17 July 2020; Revised 14 October 2020; Accepted 16 November 2020; Published 18 January 2021

Academic Editor: Antonio Ferrante

Copyright (C) 2021 Phyllis W. Muturi et al. This is an open access article distributed under the Creative Commons Attribution License, which permits unrestricted use, distribution, and reproduction in any medium, provided the original work is properly cited.

\begin{abstract}
Sorghum (Sorghum bicolor (L.) Moench) is an important food crop in semi-arid tropics. The crop grain yield ranges from $0.5 \mathrm{t} / \mathrm{ha}$ to $0.8 \mathrm{t} / \mathrm{h}$ a compared to potential yields of $10 \mathrm{t} / \mathrm{h}$. The African stem borer Busseola fusca Fuller (Noctuidae) and the spotted stem borer Chilo partellus Swinhoe (Crambidae), are among the most economically important insect pests of sorghum. The two borers can cause 15\% - 80\% grain yield loss in sorghum. Mapping of QTLs associated with resistance traits to the two stem borers is important towards marker-assisted breeding. The objective of this study was to map QTLs associated with resistance traits to B. fusca and C. partellus in sorghum. $243 \mathrm{~F}_{9: 10}$ sorghum RILs derived from ICSV 745 (S) and PB 15520-1 (R) were selected for the study with 4,955 SNP markers. The RILs were evaluated in three sites. Data was collected on leaf feeding, deadheart, exit holes, stem tunnels, leaf toughness, seedling vigour, bloom waxiness, and leaf glossiness. ANOVA for all the traits was done using Genstat statistical software. Insect damage traits and morphological traits were correlated using Pearson's correlation coefficients. Genetic mapping was done using JoinMap 4 software, while QTL analysis was done using PLABQTL software. A likelihood odds ratio (LOD) score of 3.0 was used to declare linkage. Joint analyses across borer species and sites revealed 4 QTLs controlling deadheart formation; 6 controlling leaf feeding damage; 5 controlling exit holes and stem tunneling damages; 2 controlling bloom waxiness, leaf glossiness, and seedling vigour; 4 conditioning trichome density; and 6 conditioning leaf toughness. Joint analyses for B. fusca and C. partellus further revealed that marker CS132-2 colocalised for leaf toughness and stem tunneling traits on QTLs 1 and 2, respectively; thus, the two traits can be improved using the same linked marker. This study recommended further studies to identify gene(s) underlying the mapped QTLs.
\end{abstract}

\section{Introduction}

Sorghum (Sorghum bicolor (L.) Moench) is an important food crop in drought prone areas in the tropics. The crop is cultivated by more than 500 million resource-challenged smallholder farmers, mostly women [1]. The crop is an important industrial crop in East Africa and has untapped potential in bioenergy production [2]. The African stem borer, Busseola fusca Fuller (Noctuidae) and the spotted stem borer Chilo partellus Swinhoe (Crambidae), are among the most economically important insect pests of sorghum and maize in Eastern and South Africa [3]. The two stem borer species cause leaf feeding, deadheart formation, exit holes, and stem tunneling damages in cereals [3]. Stem borers are associated with grain yield loss of $15 \%-80 \%$ depending on borer species population and variety phenological stage at the time of attack [4]. Management approaches such as cultural practices and use of synthetic chemical pesticides have 
yielded little success in the management of the stem borers. Host plant resistance can reduce sorghum grain yield losses to stem borers and thus improve food security among rural households [5]. Breeding for host plant resistance is part of integrated pest management that can contribute in an economic way in the management of insect pests in indigenous cereals cultivated by resource-challenged smallholder farmers [5]. Breeding for stem borer resistance has been slow partly due to the inadequate understanding of inheritance of traits conditioning resistance to the pests. Stem borer resistance is a polygenic trait controlled by many genes of small effects [6]. Grain sorghum with dual resistance to B. fusca and C. partellus has been reported [7]. There is no information about genomic regions associated with dual resistance to $B$. fusca and C. partellus in grain sorghum. Traits such as leaf toughness, trichomes, bloom waxiness, leaf glossiness, and seedling vigour have been reported to condition resistance to borer and foliar insect resistance in cereals [5, 8-11].

Identification and mapping of quantitative trait loci (QTLs) associated with sorghum resistance to stem borers could enhance the efficiency and effectiveness in markerassisted breeding [12]. QTL mapping enhances the biological understanding of inheritance of quantitative traits, and the markers identified can be used to select for a complex trait [13]. QTL mapping using recombinant inbred lines (RILs) increases the power of QTL detection compared to the $\mathrm{F}_{2: 3}$ population because of complete homozygosity at QTLs and marker loci [14]. Marker-assisted selection for stem borer resistance can enhance breeding for B. fusca and C. partellus since traditional breeding has been unsuccessful. Genetic linkage maps are essential for localization of genes conferring resistance/tolerance to stem borer damage in sorghum [15]. Single nucleotide polymorphism (SNP) markers have become widely accepted as a tool for understanding complex genetic traits and evolution [16]. SNPs have been found to be the most efficient genetic marker for gene identification since they are codominant, highly polymorphic, and have good reproducibility [16]. SNPs represent the finest resolution of a DNA sequence [17]. The genotyping-by-sequencing approach has been employed in whole-genome sequencing to discover SNPs for mapping studies in crop plants $[18,19]$. The objective of this study was to identify and characterize QTLs associated with resistance traits to $B$. fusca and C. partellus in sorghum.

\section{Materials and Methods}

2.1. Development of Mapping Population. $243 \mathrm{~F}_{9: 10}$ recombinant inbred lines (RILs) derived from a cross between the stem borer-susceptible cultivar ICSV 745 and stem borerresistant PB 15520-1 were selected for the mapping study. The progenies and their parents had been developed following a single seed descent approach in ICRISAT, Patancheru, India [20]. The two parents were crossed, and the resulting $\mathrm{F}_{1}$ seeds were advanced to $\mathrm{F}_{2}$ by selfing of single $\mathrm{F}_{1}$ plants. The $\mathrm{F}_{2}$ seeds were selfed and the resulting $\mathrm{F}_{3}$ population grown in progeny rows [20]. Single sorghum plants in each of the progeny row were selfed and the process continued up to the $\mathrm{F}_{9}$ generation [20]. Seeds from the $\mathrm{F}_{9}$ sorghum plants of each row were bulked to produce the $243 \mathrm{~F}_{9: 10}$ RILs used in this study.

\subsection{Experimental Design, Site, and Source of Stem Borer} Larvae. The 243 RILs along with their parents were imported from the International Crops Research Institute for the SemiArid Tropics (ICRISAT), Patancheru, India to Kenya. The sorghum plants were phenotyped at Embu and Kabete for resistance against $B$. fusca for one season in each environment and at Kiboko for resistance against $C$. partellus for two seasons thus totaling to four environments. Each experiment in each site was laid out in a $25 \times 10$ alpha-lattice design consisting of twenty-five plots in ten blocks, replicated twice. Each plot consisted of $2 \mathrm{~m}$ rows with plants spaced at $0.75 \mathrm{~m} \times 0.25 \mathrm{~m}$ inter- and intra-rows, respectively. Firstinstar neonates of the two borer species were obtained from the International Centre of Insect Physiology and Ecology (ICIPE), Nairobi, Kenya. At 30 days after sowing, five plants in each row were tagged and artificially infested with five larvae of the respective stem borer species using a camel hair brush as described by Singh et al. [21] in all the three sites.

\subsection{Phenotypic Data Collection and Data Analysis. Data on} stem borer leaf feeding damage, deadheart incidence, number of exit holes, and stem tunnel length were scored as described by Muturi et al. [7]. Morphological traits measured included leaf toughness, seedling vigour, bloom waxiness, leaf glossiness, and total grain yield as described by Kumar et al. [22]. Data were subjected to analysis of variance using the residual maximum likelihood model (ReML) in Genstat Version 14 statistical package. The predicted means for each genotype were estimated with genotypes as fixed and reps as random effects in individual and across environment analyses. Phenotypic and genetic correlation coefficients were calculated from adjusted entry means across environments for each parameter. Estimates of variance components, including genotypic variance $\left(\sigma^{2} g\right)$, genotype $\times$ environment interaction $\left(\sigma^{2} g \times e\right)$, and residual $\left(\sigma^{2}\right)$ were calculated by equating the mean squares to their expected values as described by Shimelis and Shiringani [23]. Heritability $(H)$ was estimated using Meta-R software version 6 using $H=$ $\left(\partial_{g}^{2}\right) /\left(\partial_{g}^{2}+\partial_{g \times e /(r)}^{2}+\partial_{e l(r \times e n v)}^{2}\right)$, where $\partial_{g}^{2}=$ genotypic variance, $\partial_{g \times e}^{2}=$ genotype by environment variance, $\partial_{e}^{2}=$ error variance, $r=$ number of replications, and env $=$ number of environments as described by Hallauer and Miranda, [24]. Direct and indirect effect analyses were conducted using path analysis to study interrelationship among resistance parameters and their relationship to grain yield reduction [25]. Genotypic and phenotypic correlation coefficients were calculated following the method described by Holland [26].

2.4. DNA Extraction and Quantification. Leaf tissue from the parental lines and the 243 RILs were harvested from 10-dayold sorghum seedlings. DNA was extracted according to [27]. The quality of DNA in each sample was checked using $0.8 \%$ agarose gel stained with ethidium bromide. Each well of the agarose gel was loaded with $5 \mu \mathrm{l}$ of the sample, and the gel was allowed to run at $100 \mathrm{~V}$ for 5 minutes. After 
electrophoresis, DNA banding patterns on the gel were visualized under UV light. A smear of DNA indicated poor quality, and the DNA was re-extracted, whereas a clear band indicated good quality DNA. The quantity of DNA in each sample was assessed using a fluorescence spectrophotometer (Switzerland) by staining the DNA with PicoGreen ${ }^{\mathrm{TM}}(1 / 200$ dilution). The DNA concentration of each sample was calculated and then normalized to $2.5 \mathrm{ng} / \mu \mathrm{l}$ for the PCR.

2.5. Scoring of Sequenced Products and Construction of Linkage Map. The SNP markers screened on the RILs were scored as follows: $\mathrm{A}=$ homozygote carrying allele from female parent (ICSV 745); B = homozygote carrying allele from male parent (PB 15520-1); and - = missing data for an individual at a locus. The genotypic data was used to construct a genetic linkage map, which spanned 4,692.4 cM, with a total of 4,955 SNP markers distributed into the 10 sorghum linkage groups (Figure 1).

Segregation of each marker was tested with a chi-square goodness of fit test to the expected Mendelian segregation ratio $(1: 1)$ of parental configuration. The names of the markers were coded for ease of analysis (Supplementary Material Table 14). The markers that did not conform to the expected segregation ratio were excluded from the analysis. Three-point linkage analysis was performed for each linkage group, and the most saturated linkage was adopted as described by Ooijen [28]. After the addition of each loci, a ripple was used to verify local locus orders [28].

2.6. QTL Analysis. QTL analyses were performed on morphological data and on leaf feeding, deadheart, exit holes, and stem tunneling damage under infestation with $B$. fusca at the Kabete and Embu sites and the same traits under infestation with C. partellus at the Kiboko site. Joint analysis was also done using averaged means across environments and insect species. Composite interval mapping (CIM) was performed on the data using PLABQTL software, version 1.2 [29]. Whole-genome scan with CIM was conducted using an automatic cofactor selection model to determine additive effects at individual QTL, and the $F$ value of ten options were selected. Cofactors were chosen by step-wise regression and Akaike's information criterion (AIC) of 3.0 with the "cov" statement in PLABQTL. Dependence of QTL estimation on sampling effects was estimated by a five-fold cross validation by dividing the genotypes into five subsets. The LOD threshold for declaring a putative QTL was set to 3.0 after performing 1,000 permutation tests (type I error level $\alpha=10 \%$ ). All QTLs identified in this study explained $\geq 10 \%$ of the total phenotypic variation and were thus classified as major QTLs [30].

\section{Results}

\subsection{Phenotypic Analysis}

3.1.1. Results for Combined Analyses of Variance across Environments. The combined results for the two borer species suggested that plant damage (deadheart formation, leaf feeding damage, exit holes, and stem tunnels) and agro-morphological traits (seedling vigour and bloom wax- iness) evaluated in this study were influenced significantly $(P<0.01)$ by borer species tested, genotype, and the environment where the experiment was conducted (Table 1).

Results of mean squares for leaf feeding, deadheart, exit holes and morphological traits at Kiboko are presented in Table 2. There were significant differences observed for all the traits measured except for leaf feeding damage. Exit holes and stem tunneling damages were the only plant damage traits that were significantly $(P<0.01)$ influenced by genotype by season interaction (Table 2). Results of mean squares for leaf feeding, deadheart, exit holes, and morphological traits at Embu are presented in Table 3. There were significant $(P<0.01)$ genotypic differences on all the traits evaluated at Embu site for B. fusca (Table 3).

Results of mean squares for leaf feeding, deadheart, exit holes, and morphological traits at Kabete are presented in Table 4 . Genotype significantly $(P<0.01)$ influenced all the traits evaluated except leaf feeding damage (Table 4$)$. Heritability estimates and their standard errors for the sorghum damage and morphological traits across the three environments are presented in Table 5. It was noted that heritability estimates for $C$. partellus at Kiboko were generally low for most of the traits compared to the two other sites where $B$. fusca was tested.

The contribution of B. fusca damage parameters to total grain yield through leaf feeding, deadheart, stem tunnels, and number of exit hole damages at Embu are presented in Table 6. Damage effects were partitioned into direct and indirect associations through path coefficient analysis, and grain yield was used as the resultant variable (Table 6). Deadheart, exit holes, leaf feeding, and stem tunneling damages had a negative correlation with grain yield. Deadheart had a significant direct positive effect on grain yield supported by an indirect positive effect through stem tunneling and indirect negative effects through the number of exit holes and leaf feeding damages. Exit holes had a direct positive effect on grain yield supported by indirect positive effects through deadheart and leaf feeding damages and an indirect negative effect through stem tunneling. Leaf feeding had a direct positive effect on grain yield supported by indirect positive effects through deadheart and the number of exit holes and an indirect negative effect through stem tunneling. Stem tunneling had a direct positive effect on grain yield supported by indirect positive effects through deadheart, number of exit holes, and leaf feeding damages. The contribution of $B$. fusca damage parameters to total grain yield through leaf feeding, deadheart formation, stem tunnels, and number of exit hole damages at Kabete is presented in Table 7.

Deadheart, exit holes, leaf feeding, and stem tunneling damages had a negative correlation with grain yield. Deadheart had a direct positive effect on grain yield supported by indirect positive effects on exit holes, leaf feeding, and stem tunneling damages. The number of exit holes had a direct positive effect on grain yield supported by indirect positive effects through deadheart, leaf feeding, and stem tunneling damages. Leaf feeding damage had a direct positive effect on grain yield supported by an indirect positive effect through deadheart damage and indirect negative effects through exit hole and stem tunneling damages. Stem 

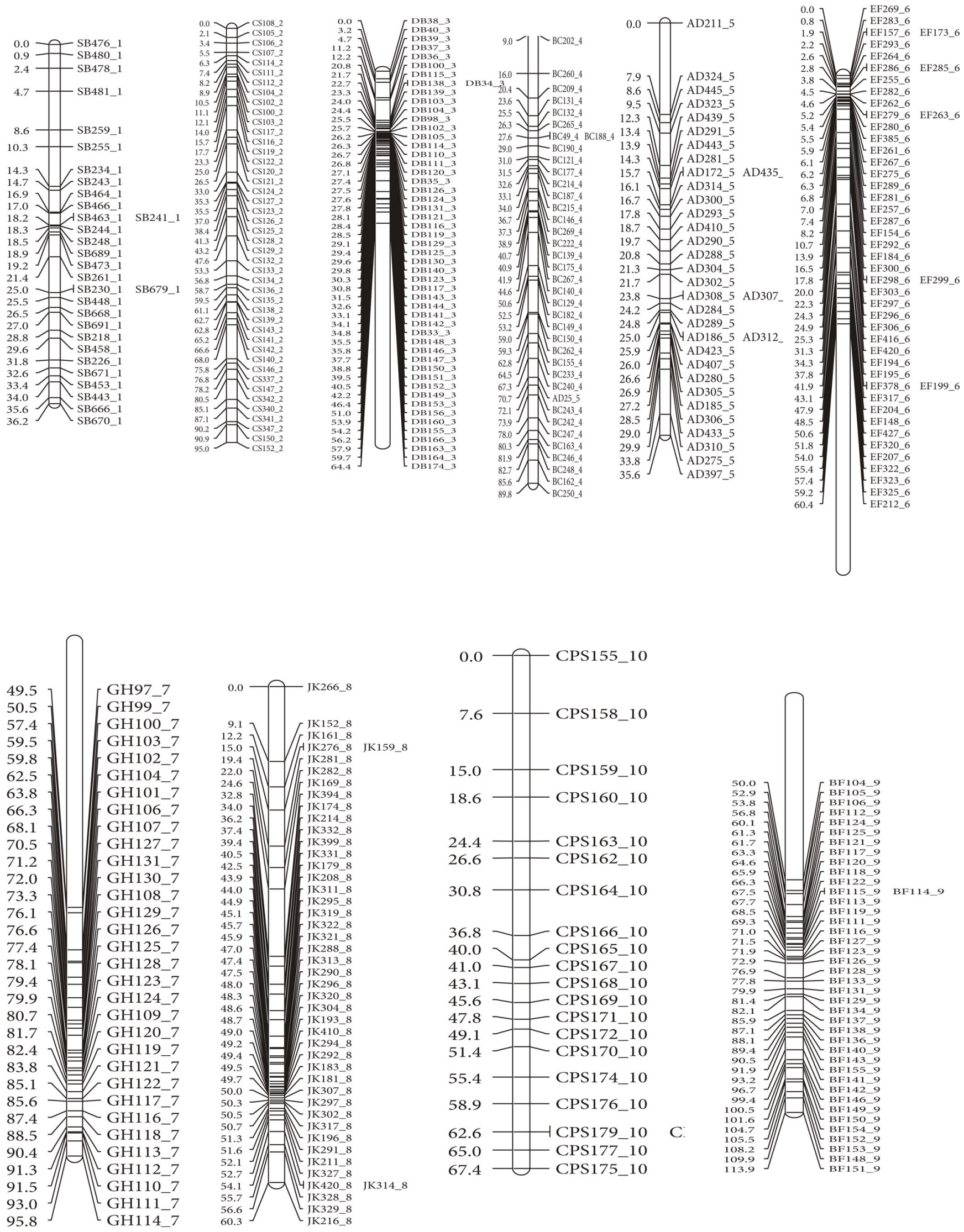

FIGURE 1: Genetic map of ICSV $745 \times$ PB 15520 recombinant inbred lines of sorghum generated using 4,955 polymorphic SNP markers. 
TABLE 1: Combined analyses of variance across environments.

\begin{tabular}{|c|c|c|c|c|c|c|c|}
\hline Source & DF & $\mathrm{DH}$ & LD & $\mathrm{EH}$ & ST & VG & BW \\
\hline Rep & 1 & 60.3 & 1176.8 & 397.4 & 5432.6 & 92.4 & 20.4 \\
\hline Borer spp. & 1 & $109506.8^{* *}$ & $417327^{* *}$ & $701.7^{* *}$ & $6304.2^{* *}$ & $5.6^{*}$ & $28.4^{* *}$ \\
\hline Genotype & 265 & $547.1 \mathrm{~ns}$ & $527.4 \mathrm{~ns}$ & $137.9^{* *}$ & $904^{* *}$ & $1.2^{* *}$ & $3.2^{* *}$ \\
\hline Environment & 3 & $153767.7^{* *}$ & $82463.8^{* *}$ & $4338.2^{* *}$ & $43160.9^{* *}$ & $8.1^{* *}$ & $977.9^{* *}$ \\
\hline Borer_spp ·genotype & 265 & $506.9 \mathrm{~ns}$ & $511.3 \mathrm{~ns}$ & $60.1^{* *}$ & $341.2^{* *}$ & $0.9 \mathrm{~ns}$ & $2 \mathrm{~ns}$ \\
\hline Genotype - environment & 795 & $323.9 \mathrm{~ns}$ & $330.5 \mathrm{~ns}$ & $27 \mathrm{~ns}$ & $187.4 \mathrm{~ns}$ & $0.6 \mathrm{~ns}$ & $1.5 \mathrm{~ns}$ \\
\hline Residual & 9302 & 471.2 & 585.8 & 28.9 & 217.2 & 0.9 & 2.1 \\
\hline
\end{tabular}

$*$ and $* *$ indicate that data are significant at the $\leq 0.05$ and $\leq 0.01$ probability levels, respectively; ns=nonsignificant; $\mathrm{DF}=\mathrm{degrees}$ of freedom; $\mathrm{DH}=\mathrm{deadheart}$ (\%); $\mathrm{LD}=$ leaf feeding damage (\%); $\mathrm{EH}=$ exit holes; $\mathrm{ST}=$ stem tunneling; $\mathrm{VG}=$ seedling vigour; $\mathrm{BW}=$ bloom waxiness; Borer_spp ·genotype=borer spp. by genotype interaction; Genotype $\cdot$ environment=genotype by environment interaction.

TABle 2: Mean squares for Chilo partellus damage and morphological traits at the Kiboko site.

\begin{tabular}{lcccccccc}
\hline Source & DF & DH & LD & EH & ST & VG & BW & GL \\
\hline Rep & 1 & 9957.3 & 1276.3 & 357.74 & 8260.1 & 96.6018 & 136.799 & 10.3224 \\
Genotype & 265 & 260.5 & 459.6 & $80.66^{* *}$ & $591.3^{* *}$ & $0.9825^{* *}$ & $2.598^{* *}$ & $0.3900^{* *}$ \\
Season & 1 & $395099.3^{* *}$ & 123.3 & $12714.94^{* *}$ & $129477.7^{* *}$ & $19.058^{* *}$ & $774.727^{* *}$ & $1.1911^{*}$ \\
Genotype - season & 265 & 262.3 & 382.6 & $45.03^{* *}$ & $352^{* *}$ & 0.7023 & 1.567 & 0.1344 \\
Residual & 4786 & 227.7 & 450.7 & 30.52 & 235.2 & 0.6442 & 1.724 & 0.1915 \\
\hline
\end{tabular}

** indicates that data is significant at the $\leq 0.01$ probability level; $\mathrm{DF}=$ degrees of freedom; $\mathrm{DH}=$ deadheart damage; $\mathrm{LD}=$ leaf feeding damage; $\mathrm{EH}=$ exit holes; $\mathrm{ST}=$ stem tunneling; $\mathrm{VG}=$ seedling vigour; $\mathrm{BW}=$ bloom waxiness; $\mathrm{GL}=$ glossiness.

TABle 3: Mean squares for Busseola fusca damage and morphological traits at the Embu site.

\begin{tabular}{|c|c|c|c|c|c|c|c|c|}
\hline Source & DF & $\mathrm{DH}$ & LD & $\mathrm{EH}$ & ST & VG & GL & BW \\
\hline Rep & 1 & 18491 & 5552.1 & 122.36 & 594.3 & 0.1295 & 3.9774 & 11.29 \\
\hline Genotype & 265 & $981.6 * *$ & $945 * *$ & $65.2 * *$ & $377.5 * *$ & $1.6923 * *$ & $0.5039 * *$ & $3.94 * *$ \\
\hline Residual & 265 & 440 & 329.5 & 22.6 & 161 & 0.9548 & 0.3253 & 1.828 \\
\hline
\end{tabular}

* and $* *$ indicate that data are significant at the $\leq 0.05$ and $\leq 0.01$ probability levels, respectively; $\mathrm{DF}=$ degrees of freedom; $\mathrm{DH}=$ deadheart damage; $\mathrm{LD}=$ leaf feeding damage; $\mathrm{EH}=$ exit holes; $\mathrm{ST}=$ stem tunneling; $\mathrm{VG}=$ seedling vigour; $\mathrm{GL}=$ leaf glossiness; $\mathrm{BW}=$ bloom waxiness.

TABle 4: Mean squares for Busseola fusca damage and morphological traits at the Kabete site.

\begin{tabular}{lcccccccc}
\hline Source & DF & DH & LD & EH & ST & VG & GL & BW \\
\hline Rep & 1 & 427.1 & 37498.3 & 3.99 & 33 & 0.5305 & 3.9774 & 16.9286 \\
Genotype & 265 & $521.1 *$ & 243.1 & $88.12 * *$ & $487.5 * *$ & $0.60 * *$ & $0.34 * *$ & $1.63 * *$ \\
Residual & 265 & 412.3 & 366.4 & 28.64 & 212 & 0.33 & 0.2054 & 0.622 \\
\hline
\end{tabular}

* and $* *$ indicate that data are significant at the $\leq 0.05$ and $\leq 0.01$ probability levels, respectively; $\mathrm{DF}=$ degrees of freedom; $\mathrm{DH}=$ deadheart damage; $\mathrm{LD}=$ leaf feeding damage; $\mathrm{EH}=$ exit holes; $\mathrm{ST}=$ stem tunneling; $\mathrm{VG}=$ seedling vigour; $\mathrm{GL}=$ leaf glossiness; $\mathrm{BW}=$ bloom waxiness.

TABLE 5: Heritability estimates for stem borer damage and morphological traits at the three sites.

\begin{tabular}{|c|c|c|c|c|c|c|}
\hline \multirow{2}{*}{ Site } & \multicolumn{6}{|c|}{ Trait } \\
\hline & $\mathrm{DH}$ & $\mathrm{LD}$ & $\mathrm{EH}$ & ST & VG & BW \\
\hline Kabete (B. fusca) & 0.208 & 0.651 & 0.293 & 0.206 & 0.436 & 0.536 \\
\hline Embu (B. fusca) & 0.551 & 0.651 & 0.273 & 0.212 & 0.435 & 0.536 \\
\hline Kiboko (C. partellus) & 0.199 & 0.151 & 0.182 & 0.172 & 0.317 & 0.194 \\
\hline
\end{tabular}

$\mathrm{DH}=$ deadheart damage; $\mathrm{LD}=$ leaf feeding damage; $\mathrm{EH}=$ exit holes; $\mathrm{ST}=$ stem tunneling; $\mathrm{VG}=$ =eedling vigour; $\mathrm{BW}=$ bloom waxiness. 
TABLE 6: Direct and indirect effects of B. fusca damage traits on total grain yield at Embu site.

\begin{tabular}{|c|c|c|c|c|c|c|}
\hline \multirow{2}{*}{ Character } & \multicolumn{2}{|c|}{ Correlation with } & \multicolumn{4}{|c|}{ Indirect effect via } \\
\hline & Grain yield & Direct effect & $\mathrm{DH}$ & $\mathrm{EH}$ & LD & ST \\
\hline $\mathrm{DH}$ & -0.96 & $42.62 * *$ & - & -0.0012 & -0.0007 & 0.004 \\
\hline $\mathrm{EH}$ & -0.96 & $4.927 * *$ & 0.0026 & - & 0.0132 & -0.0325 \\
\hline LD & -0.96 & $37.62 * *$ & 0.0005 & 0.0031 & - & -0.0001 \\
\hline ST & -0.96 & $19.32 * *$ & 0.0001 & 0.001 & 0.0057 & - \\
\hline
\end{tabular}

$\mathrm{DH}=$ deadheart damage; $\mathrm{EH}=$ number of exit holes; $\mathrm{LD}=$ leaf feeding damage; $\mathrm{ST}=$ stem tunneling damage; $* *$ indicates that data is significant at the $P \leq 0.01$ probability level.

TABLE 7: Direct and indirect effects of $B$. fusca damage traits on total grain yield at Kabete site.

\begin{tabular}{lccccc}
\hline \multirow{2}{*}{ Character } & \multicolumn{2}{c}{ Correlation with } & \multicolumn{2}{c}{ Indirect effect via } \\
& Grain yield & Direct effect & DH & EH & LD \\
\hline DH & -0.87 & $60.37 * *$ & - & 0.0009 & 0.0008 \\
EH & -0.87 & $4.078 * *$ & 0.0164 & - & 0.004 \\
LD & -0.87 & $71.24 * *$ & 0.0018 & -0.0006 & -0.0066 \\
ST & -0.87 & $18.10 * *$ & -0.0053 & -0.0071 & -0.0005 \\
\hline
\end{tabular}

$\mathrm{DH}=$ deadheart damage; $\mathrm{EH}=$ number of exit holes; $\mathrm{LD}=$ leaf feeding damage; $\mathrm{ST}=$ stem tunneling damage; $* *$ indicates that data is significant at the $P \leq 0.01$ probability level.

TABLE 8: Direct and indirect effects of $C$. partellus damage traits on total grain yield at Kiboko site.

\begin{tabular}{lccccc}
\hline \multirow{2}{*}{ Character } & \multicolumn{2}{c}{ Correlation with } & \multicolumn{2}{c}{ Indirect effect via } \\
& Grain yield & Direct effect & DH & EH & LD \\
\hline DH & -0.97 & $68.11 * *$ & - & -0.0006 & -0.0061 \\
EH & -0.97 & $6.003 * *$ & -0.0015 & - & 0.0056 \\
LD & -0.97 & $36.93 * *$ & -0.0013 & -0.0060 & 0.0055 \\
ST & -0.97 & $16.69 * *$ & 0.00149 & 0.0016 & -0.0003 \\
\hline
\end{tabular}

** indicates that data is significant at the $\leq 0.01$ probability level; $\mathrm{DH}=$ deadheart damage; $\mathrm{EH}=$ number of exit holes; $\mathrm{LD}=$ leaf feeding damage; $\mathrm{ST}=$ stem tunneling damage.

tunneling had direct positive effects on grain yield supported by indirect negative effects through deadheart, the number of exit holes, and leaf feeding damages. The contribution of $C$. partellus damage traits to total grain yield through leaf feeding, deadheart, stem tunneling, and the number of exit hole damages at Kiboko are presented in Table 8.

Deadheart, exit holes, leaf feeding, and stem tunneling damages had a negative correlation with grain yield (Table 8). Deadheart had a direct positive effect on grain yield supported by an indirect positive effect through stem tunneling and an indirect negative effect through exit holes and leaf feeding damages. Exit holes had direct positive effects on grain yield supported by an indirect positive effect through leaf feeding and stem tunneling damages and an indirect positive effect through deadheart damage. Leaf feeding had a direct positive effect on grain yield supported by indirect negative effects through deadheart, exit holes, and stem tunneling damages. Stem tunneling had a direct positive effect on grain yield supported by indirect positive effects through deadheart, exit holes, and leaf feeding damages.
3.1.2. Correlations of Means among Stem Borer Damage and Agro-morphological Traits. The results for correlations of mean for B. fusca damage and agro-morphological traits in Embu, Kenya are presented in Table 9. A significant positive correlation was observed between panicle length and plant height ( $r=0.45, P \leq 0.001)$, implying that taller plants had a long panicle length. Stem tunneling had a significant positive association with plant height $(r=0.18, P=0.0057)$ and with exit holes $(r=0.71, P \leq 0.001)$. Seedling vigour had a positive and significant relationship with plant height $(r=0.21, P=0.0011)$. Exit holes had a significant positive relationship with deadheart damage $(r=0.15, P=0.02)$. Leaf damage had a significant positive relationship with deadheart damage $(r=0.25, P \leq 0.001)$. A significant positive correlation was observed between trichome density and leaf glossiness $(r=0.18, P=0.0039)$, with seedling vigour $(r=0.14$, $P=0.033)$, and with bloom waxiness $(r=0.17, P=0.0075)$. A significant positive correlation was recorded between seedling vigour and panicle length $(r=0.13, P=0.03)$. Bloom waxiness had a significant positive correlation with seedling 
TABLE 9: Correlation coefficients between B. fusca damage and agro-morphological traits at Embu site.

\begin{tabular}{|c|c|c|c|c|c|c|c|c|c|c|c|c|}
\hline $\mathrm{PH}$ & - & & & & & & & & & & & \\
\hline $\mathrm{DH}$ & -0.03 & - & & & & & & & & & & \\
\hline $\mathrm{EH}$ & 0.12 & $0.15 *$ & - & & & & & & & & & \\
\hline FL & 0.07 & -0.03 & 0.01 & - & & & & & & & & \\
\hline GL & 0.05 & -0.08 & 0.01 & -0.07 & - & & & & & & & \\
\hline LD & 0.06 & $0.25 * *$ & -0.07 & -0.01 & 0.12 & - & & & & & & \\
\hline PL & $0.45 * *$ & 0.03 & 0.06 & 0.10 & 0.07 & 0.12 & - & & & & & \\
\hline ST & $0.18 * *$ & 0.11 & $0.71 * *$ & 0.03 & 0.01 & -0.07 & 0.12 & - & & & & \\
\hline TR & 0.01 & 0.02 & -0.06 & 0.00 & $0.18 * *$ & 0.06 & -0.01 & -0.09 & - & & & \\
\hline VG & $0.21 * *$ & $-0.40 * *$ & $-0.20 * *$ & -0.04 & $0.14 *$ & -0.01 & $0.13 *$ & -0.06 & -0.02 & - & & \\
\hline BW & 0.11 & $-0.39 * *$ & $-0.33 * *$ & -0.01 & $0.17 * *$ & -0.09 & 0.07 & $-0.20 * *$ & 0.02 & $0.60 * *$ & - & \\
\hline \multirow[t]{2}{*}{ YLD } & 0.09 & 0.08 & $0.15 *$ & 0.06 & -0.07 & 0.09 & $0.17 * *$ & 0.10 & 0.05 & -0.09 & -0.06 & - \\
\hline & $\mathrm{PH}$ & $\mathrm{DH}$ & $\mathrm{EH}$ & $\mathrm{FL}$ & GL & $\mathrm{LD}$ & PL & ST & TR & VG & BW & YLD \\
\hline
\end{tabular}

$*$ and $* *$ indicate that data are significant at the $\leq 0.05$ and $\leq 0.01$ probability levels, respectively; $\mathrm{PH}=$ plant height; $\mathrm{DH}=\mathrm{deadheart}$ EH=exit holes; $\mathrm{FL}=$ days to flowering; GL=leaf glossiness; $\mathrm{LD}=$ leaf damage; $\mathrm{PL}=$ panicle length; $\mathrm{ST}=$ stem tunneling; $\mathrm{TR}=$ trichome density; VG=seedling vigour; $\mathrm{BW}=$ bloom waxiness; YLD=total grain yield.

TABle 10: Correlation coefficients between B. fusca damage and agro-morphological traits at Kabete site.

\begin{tabular}{|c|c|c|c|c|c|c|c|c|c|c|c|c|}
\hline $\mathrm{DH}$ & - & & & & & & & & & & & \\
\hline $\mathrm{EH}$ & 0.05 & - & & & & & & & & & & \\
\hline FL & 0.07 & $-0.13 *$ & - & & & & & & & & & \\
\hline GL & -0.09 & -0.09 & 0.11 & - & & & & & & & & \\
\hline LD & $0.31 * *$ & 0.02 & 0.05 & 0.01 & - & & & & & & & \\
\hline $\mathrm{PH}$ & -0.04 & 0.10 & -0.05 & -0.07 & -0.01 & - & & & & & & \\
\hline PL & 0.02 & $0.14 *$ & -0.03 & -0.05 & 0.11 & $0.16 *$ & - & & & & & \\
\hline ST & 0.05 & $0.70 * *$ & $-0.16 *$ & -0.11 & 0.03 & 0.12 & $0.15 *$ & - & & & & \\
\hline TR & -0.04 & 0.12 & 0.02 & 0.01 & -0.05 & 0.01 & -0.05 & 0.05 & - & & & \\
\hline VG & $-0.38 * *$ & $-0.15 *$ & -0.03 & $0.13 *$ & -0.01 & 0.08 & $-0.14 *$ & $-0.17 *$ & 0.04 & - & & \\
\hline BW & -0.09 & 0.03 & 0.07 & $0.20 * *$ & 0.12 & -0.03 & 0.05 & -0.01 & 0.02 & $0.15 *$ & - & \\
\hline \multirow[t]{2}{*}{ YLD } & 0.09 & $0.32 * *$ & $-0.14 *$ & -0.09 & $0.14 *$ & $0.15 *$ & $0.30 * *$ & $0.27 * *$ & -0.07 & -0.12 & -0.00 & - \\
\hline & $\mathrm{DH}$ & $\mathrm{EH}$ & FL & GL & $\mathrm{LD}$ & $\mathrm{PH}$ & PL & ST & $\mathrm{TR}$ & VG & BW & YLD \\
\hline
\end{tabular}

$*$ and $* *$ indicate that data are significant at the $\leq 0.05$ and $\leq 0.01$ probability levels, respectively; $\mathrm{PH}=\mathrm{plant}$ height; $\mathrm{DH}=\mathrm{deadheart}$; $\mathrm{EH}=\mathrm{exit}$ holes; $\mathrm{FL}=\mathrm{days}$ to flowering; $\mathrm{GL}=$ leaf glossiness; $\mathrm{LD}=$ leaf damage; $\mathrm{PL}=$ panicle length; $\mathrm{ST}=$ stem tunneling; $\mathrm{TR}=$ trichome density; VG=seedling vigour; $\mathrm{BW}=\mathrm{bloom}$ waxiness; YLD=total grain yield.

vigour $(r=0.60, P \leq 0.001)$. A significant negative relationship was recorded between seedling vigour and deadheart formation $(r=-0.40, \quad P \leq 0.001)$ and with exit holes $(r=-20, P=0.002)$. Bloom waxiness had a significant negative correlation with deadheart damage $(r=-0.39, P \leq 0.001)$, with exit holes $(r=-0.33, P \leq 0.001)$, and with stem tunneling $(r=-20, P=0.0016)$, respectively.

The results for correlations of mean for B. fusca damage and agro-morphological traits at Kabete, Kenya are presented in Table 10.

Leaf feeding had a significant positive correlation with deadheart damage $(r=0.31, P \leq 0.001)$. Stem tunneling had a significant positive relationship with exit holes $(r=0.70$ , $P \leq 0.001$ ). Bloom waxiness had a significant positive correlation with leaf glossiness $(r=0.20, P=0.002)$ and with seedling vigour $(r=0.15, P=0.02)$. Yield had a significant positive correlation with plant height $(r=0.15, P=0.021)$ and with panicle length $(r=0.30, P \leq 0.001)$. Seedling vigour had a significant negative correlation with deadheart damage $(r=-0.38, P \leq 0.001)$, with exit holes $(r=-0.15$, $P=0.02)$, and with stem tunneling $(r=-0.17, P=0.008)$. Days to $50 \%$ flowering had a significant negative correlation with the number of exit holes $(r=-0.13, P=0.04)$.

The results for correlations of mean for C. partellus damage and agromorphological traits at Kiboko, Kenya are presented in Table 11. Stem tunneling had a significant positive correlation with exit holes $(r=0.68, P \leq 0.001)$. Days to $50 \%$ flowering had a positive correlation with leaf damage $(r=0.17, P=0.008)$ and with plant height $(r=0.13, P=0.04)$. Panicle length had a significant positive relationship with 
TABLE 11: Correlation coefficients between C. partellus damage and agro-morphological traits at Kiboko site.

\begin{tabular}{|c|c|c|c|c|c|c|c|c|c|c|c|}
\hline $\mathrm{DH}$ & - & & & & & & & & & & \\
\hline $\mathrm{EH}$ & -0.10 & - & & & & & & & & & \\
\hline FL & -0.09 & 0.01 & - & & & & & & & & \\
\hline GL & 0.01 & 0.00 & 0.02 & - & & & & & & & \\
\hline $\mathrm{LD}$ & 0.09 & -0.01 & $0.17 * *$ & 0.05 & - & & & & & & \\
\hline $\mathrm{PH}$ & 0.03 & 0.12 & $0.13 *$ & 0.04 & 0.07 & - & & & & & \\
\hline PL & -0.02 & 0.07 & 0.12 & -0.09 & -0.05 & $0.27 * *$ & - & & & & \\
\hline ST & 0.02 & $0.68 * *$ & $-0.13 *$ & -0.03 & -0.04 & 0.00 & 0.03 & - & & & \\
\hline VG & -0.06 & -0.03 & $-0.33 * *$ & -0.03 & $-0.13 *$ & -0.00 & -0.01 & $0.13 *$ & - & & \\
\hline BW & -0.05 & -0.09 & 0.12 & 0.03 & 0.04 & -0.03 & $0.13 *$ & $-0.26 * *$ & $0.13 *$ & - & \\
\hline \multirow[t]{2}{*}{ YLD } & 0.07 & 0.06 & -0.08 & -0.01 & $-0.16 *$ & 0.12 & $0.34 * *$ & $0.15 *$ & 0.02 & -0.02 & - \\
\hline & $\mathrm{DH}$ & $\mathrm{EH}$ & $\mathrm{FL}$ & GL & LD & $\mathrm{PH}$ & $\mathrm{PL}$ & ST & VG & BW & YLD \\
\hline
\end{tabular}

$*$ and $* *$ indicate that data are significant at the $\leq 0.05$ and $\leq 0.01$ probability levels, respectively; $\mathrm{PH}=$ plant height; $\mathrm{DH}=$ deadheart; $\mathrm{EH}=\mathrm{exit}$ holes; $\mathrm{FL}=\mathrm{days}$ to flowering; GL=leaf glossiness; LD=leaf damage; PL=panicle length; ST=stem tunneling; TR=trichome density; VG=seedling vigour; $\mathrm{BW}=$ bloom waxiness; YLD=total grain yield.

plant height $(r=0.27, P \leq 0.001)$, with bloom waxiness $(r=0.13, P=0.04)$, and with total grain yield $(r=0.34, P \leq$ $0.001)$. Seedling vigour had a significant positive correlation with bloom waxiness $(r=0.13, P=0.04)$. Days to $50 \%$ flowering had a significant negative correlation with stem tunneling $(r=-0.13, P=0.04)$ and with seedling vigour $(r=-0.33$, $P \leq 0.001)$. Stem tunneling had a significant negative relationship with bloom waxiness $(r=-0.26, P \leq 0.001)$. Leaf feeding damage had a significant negative correlation with seedling vigour $(r=-0.13, P=0.04)$ and with total grain yield $(r=-0.16, P=0.01)$.

3.1.3. QTL Mapping. QTL analysis with composite interval mapping was performed for the damage traits under artificial infestation with B. fusca at the Embu and Kabete sites, and the same traits were evaluated for C. partellus at Kiboko under artificial infestation as described in Materials and Methods. The results for damage and morphological traits are shown in Table 12. Three QTLs for deadheart damage due to $B$. fusca were detected on chromosomes 1,3 , and 5 (flanked by markers SB261_1, DB103_3, and AD323_5) at Embu (Table 12) that explained 3.9\% of the phenotypic variation, with individual QTLs accounting for 7.5\% - 11.2\%. A simultaneous fit with all the three QTLs based on cross validation explained $28.3 \%$ of the adjusted genetic variance. The additive gene action ranged from -7.79 to 35.13 . Two of the QTLs on chromosomes 1 and 5 (flanked by markers SB261_1 and AD323_5) were from the susceptible parent, while the remaining QTLs on chromosome 3 (marker DB103_3) came from the resistant parent (PB 15520-1). The resistant parent contributed to less deadheart damage, which is a putative trait associated with resistance to stem borers in sorghum.

Five QTLs for leaf feeding damage due to $B$. fusca at Embu site were detected on chromosomes 2 and 10 (flanked by markers CS115_2, CS190_2, CS389_2, CS414_2, and CPS162_10, respectively) (Table 12). These explained $10.5 \%$ of the phenotypic variation, with individual QTLs accounting for 7.1\% - 9.1\%. A simultaneous fit with all the five QTLs based on cross validation explained $40.6 \%$ of the adjusted genetic variance. The additive gene action ranged from -6.48 to 8.13 . Three of the QTLs on chromosomes 2 and 10 (flanked by markers CS190_2, CS389_2, and CPS162_10) came from the susceptible parent. The rest of the QTLs on chromosome 2 (flanked by markers CS115_2 and CS414_2) came from the resistant parent (PB 15520-1), which contributed to less leaf feeding damage, which is a trait associated with resistance to stem borers in sorghum.

One QTL for exit hole damage due to B. fusca at Embu site was detected on chromosome 7 flanked by marker GH89_7 (Table 12). This explained 6.1\% of the phenotypic variation, with individual QTL accounting for 9\%. A simultaneous fit with the single QTL based on cross validation explained $9 \%$ of the adjusted genetic variance. The additive gene action was -1.42. This QTL came from the resistant parent (PB 15520-1) which contributed to less exit hole damage, a trait associated with resistance to stem borers in sorghum.

Two QTLs for stem tunneling damage by B. fusca at Embu site were detected on chromosomes 7 and 9, respectively (flanked by markers GH87_7 and BF123_9) (Table 12). These explained $5.9 \%$ of the phenotypic variation, with individual QTLs accounting for $8.1 \%$ - 8.2\%. A simultaneous fit with the two QTLs based on cross validation explained $16.3 \%$ of the adjusted genetic variance. The additive gene action ranged from -2.39 to -7.33 . The two QTLs came from the resistant parent (PB 15520-1), an indication of the transfer of genes associated with resistance to stem tunneling by borers in sorghum.

Ten QTLs for deadheart damage due to B. fusca were detected on chromosomes 1, 2, 3, 4, 8, and 5, respectively, (flanked by markers SB691_1, CS402_2, CS259_2, CS350_2, DB172_3, DB169_3, BC149_4, JK399_8, BF97_9, and BF106_9) (Table 12). These explained $2.8 \%$ of the phenotypic variation, with individual QTLs accounting for 7.6\% - 17.5\%. A simultaneous fit with all the ten QTLs based on cross validation explained $80.6 \%$ of the adjusted genetic variance. The 
TABLE 12: QTL analyses at the three sites from the RIL sorghum population derived from ICSV $745 \times$ PB 15520-1.

\begin{tabular}{|c|c|c|c|c|c|c|c|c|c|c|c|c|}
\hline $\begin{array}{l}\text { Pest } \\
\text { species }\end{array}$ & Site & Trait & QTL & Chr. & $\begin{array}{l}\text { Position } \\
\text { (cM) }\end{array}$ & $\begin{array}{c}\text { Marker and loci } \\
\text { interval }\end{array}$ & $\begin{array}{c}\text { Supp } \\
\text { interval }\end{array}$ & LOD & $R^{2}$ & $\begin{array}{l}\text { Additive } \\
\text { effects }\end{array}$ & SE & $\begin{array}{c}\operatorname{Adj} \sigma^{2} \\
g\end{array}$ \\
\hline \multirow{29}{*}{ B. fusca } & \multirow[t]{29}{*}{ Embu } & \multirow[t]{3}{*}{$\mathrm{DH}$} & 1 & 1 & 22 & SB261_1 251-220 & $20-26$ & 3.27 & 7.5 & 35.13 & $10.154 * *$ & \\
\hline & & & 2 & 3 & 24 & DB103_3 1527-1528 & $22-26$ & 4.11 & 9.6 & -7.79 & $1.680 * *$ & \\
\hline & & & 3 & 5 & 10 & AD323_5 2718-2834 & 8_12 & 3.97 & 11.2 & 8.86 & $1.731 * *$ & 28.3 \\
\hline & & \multirow[t]{5}{*}{$\mathrm{LD}$} & 1 & 2 & 4 & CS115_2 936-927 & $2 \_6$ & 3.11 & 9.1 & -6.48 & 2.335 & \\
\hline & & & 2 & 2 & 84 & CS190_2 1011-1172 & $82-86$ & 3.55 & 8.1 & 8.13 & $1.821 * *$ & \\
\hline & & & 3 & 2 & 134 & CS389_2 1210-1041 & $132-136$ & 3.09 & 7.1 & 5.27 & 1.888 & \\
\hline & & & 4 & 2 & 148 & CS414_2 1235-1083 & $146-150$ & 3.67 & 8.7 & -8.01 & $1.687 * *$ & \\
\hline & & & 5 & 10 & 30 & CPS162_10 4621-4623 & $26-36$ & 3.26 & 7.7 & 7.04 & $2.323 * *$ & 40.6 \\
\hline & & $\mathrm{EH}$ & 1 & 7 & 26 & GH89_7 3380-3379 & $24-28$ & 3.98 & 9 & -1.42 & $0.337 *$ & 9.0 \\
\hline & & \multirow[t]{2}{*}{ ST } & 1 & 7 & 22 & GH87_7 3378-3376 & $20-24$ & 3.51 & 8.2 & -2.39 & $0.584 * *$ & \\
\hline & & & 2 & 9 & 72 & BF123_9 4190-4193 & $70-74$ & 3.48 & 8.1 & -7.33 & $1.910 * *$ & 16.3 \\
\hline & & \multirow[t]{5}{*}{$\mathrm{WX}$} & 1 & 3 & 10 & DB39_3 1463-1461 & $2-12$ & 3.65 & 14.5 & 0.471 & $0.105 * *$ & \\
\hline & & & 2 & 3 & 56 & DB155_3 1579-1590 & $54-58$ & 3.17 & 7.3 & 0.578 & $0.112 * *$ & \\
\hline & & & 3 & 3 & 144 & DB214_3 1638-1637 & $140-146$ & 3.35 & 8.1 & -2.180 & $0.469 *$ & \\
\hline & & & 4 & 6 & 24 & EF297_6 3158-3157 & $22-26$ & 3.26 & 7.4 & -3.888 & $1.085 *$ & \\
\hline & & & 5 & 9 & 46 & BF101_94168-4169 & $40-48$ & 3.03 & 7.0 & 0.844 & 0.258 & 29.8 \\
\hline & & \multirow[t]{8}{*}{ VG } & 1 & 2 & 70 & CS341_2 1162-1168 & $68-72$ & 3.51 & 8.0 & -0.394 & $0.101 * *$ & \\
\hline & & & 2 & 2 & 70 & CS341_2 1162-1168 & $68-72$ & 4.60 & 10.5 & -0.423 & $0.092 * *$ & \\
\hline & & & 3 & 2 & 140 & CS403_2 1224-1064 & $138-142$ & 3.07 & 7.1 & 0.969 & $0.277 *$ & \\
\hline & & & 4 & 5 & 10 & AD323_5 2718-2834 & 8-12 & 3.04 & 8.7 & -0.451 & $0.077 *$ & \\
\hline & & & 5 & 6 & 60 & EF325_6 3186-3073 & $58-62$ & 3.06 & 7.0 & -1.578 & $0.502 *$ & \\
\hline & & & 6 & 7 & 56 & GH99_7 3390-3391 & $52-60$ & 5.53 & 12.4 & -1.588 & $0.323 * *$ & \\
\hline & & & 7 & 7 & 58 & GH100_7 3391-3394 & $52-60$ & 5.18 & 11.6 & -1.867 & $0.414 * *$ & \\
\hline & & & 8 & 7 & 58 & GH100_7 3391-3394 & $52-60$ & 5.00 & 11.3 & -2.342 & $0.329 * *$ & 76.6 \\
\hline & & \multirow[t]{3}{*}{$\mathrm{TR}$} & 1 & 2 & 44 & CS129_2 950-953 & $40-48$ & 3.27 & 7.5 & 3.000 & 1.814 & \\
\hline & & & 2 & 2 & 64 & CS139_2 960-962 & $62-66$ & 3.21 & 7.5 & -3.732 & $0.862 *$ & \\
\hline & & & 3 & 6 & 52 & EF320_6 3181-3068 & $50-54$ & 3.83 & 8.8 & -14.970 & $3.786 * *$ & 23.8 \\
\hline & & \multirow[t]{2}{*}{ GL } & 1 & 5 & 14 & AD443_5 2838-2676 & $12-16$ & 3.08 & 7.5 & -0.696 & $0.225 * *$ & \\
\hline & & & 2 & 6 & 62 & EF211_6 3072-3194 & $60-64$ & 3.24 & 7.4 & -0.841 & $0.221 * *$ & 14.9 \\
\hline \multirow{14}{*}{ B. fusca } & \multirow[t]{14}{*}{ Kabete } & \multirow[t]{10}{*}{$\mathrm{DH}$} & 1 & 1 & 28 & SB691_1 681-208 & $26-30$ & 3.53 & 8.1 & 12.95 & $3.602 * *$ & \\
\hline & & & 2 & 2 & 138 & CS402_2 1223-1224 & $136-140$ & 3.34 & 7.6 & -7.2 & $2.177 * *$ & \\
\hline & & & 3 & 2 & 154 & CS259_2 1080-1099 & $152-168$ & 4.54 & 14.6 & 8.1 & $1.615 *$ & \\
\hline & & & 4 & 2 & 82 & CS350_2 1171-1011 & 80-84 & 3.19 & 7.3 & -8.52 & $2.359 *$ & \\
\hline & & & 5 & 3 & 70 & DB172_3 1596-1603 & $68-72$ & 8.16 & 17.5 & -6.08 & $1.140 * *$ & \\
\hline & & & 6 & 3 & 74 & DB169_3 1593-1592 & $72-78$ & 3.91 & 9 & -5.32 & $1.229 * *$ & \\
\hline & & & 7 & 4 & 58 & BC149_4 2249-2250 & $52-60$ & 3.29 & 7.7 & 5.77 & $1.590 * *$ & \\
\hline & & & 8 & 8 & 40 & JK399_8 4047-3979 & $38-42$ & 4.38 & 9.9 & -20.68 & $5.332 * *$ & \\
\hline & & & 9 & 9 & 42 & BF97_9 4164-4168 & $38-46$ & 4.96 & 11.2 & 9.67 & $2.373 * *$ & \\
\hline & & & 10 & 9 & 56 & BF106_9 4173-4179 & $52-58$ & 5.19 & 11.7 & -14.34 & $3.455 * *$ & 80.6 \\
\hline & & \multirow[t]{4}{*}{$\mathrm{LD}$} & 1 & 2 & 140 & CS403_2 1224-1064 & $138-142$ & 3.01 & 7 & -9.54 & $2.926 * *$ & \\
\hline & & & 2 & 2 & 8 & CS111_2 932-933 & 6_10 & 5.05 & 12.6 & 6.56 & $0.863 * *$ & \\
\hline & & & 3 & 3 & 132 & CS397_2 1218-1219 & $130-134$ & 5.41 & 12.1 & 4.15 & $0.902 * *$ & \\
\hline & & & 4 & 4 & 64 & DB164_3 1588-1598 & $62-66$ & 4.53 & 10.2 & -3.37 & $0.834 * *$ & \\
\hline
\end{tabular}


TABle 12: Continued.

\begin{tabular}{|c|c|c|c|c|c|c|c|c|c|c|c|c|}
\hline $\begin{array}{l}\text { Pest } \\
\text { species }\end{array}$ & Site & Trait & QTL & Chr. & $\begin{array}{l}\text { Position } \\
\text { (cM) }\end{array}$ & $\begin{array}{c}\text { Marker and loci } \\
\text { interval }\end{array}$ & $\begin{array}{l}\text { Supp } \\
\text { interval }\end{array}$ & LOD & $R^{2}$ & $\begin{array}{c}\text { Additive } \\
\text { effects }\end{array}$ & SE & $\begin{array}{c}\operatorname{Adj} \sigma^{2} \\
g\end{array}$ \\
\hline & & & 5 & 6 & 72 & EF334_6 3195-3079 & $70-74$ & 3.3 & 7.6 & -14.42 & $4.207 * *$ & \\
\hline & & & 6 & 8 & 18 & m08/014.9 3924-3929 & $14-22$ & 3.17 & 7.7 & -4.3 & $3.193 * *$ & \\
\hline & & & 7 & 10 & 12 & CPS158_10 4617-4618 & 6_16 & 3.24 & 9.6 & 4.07 & $1.032 *$ & 66.8 \\
\hline & & $\mathrm{EH}$ & 1 & 2 & 62 & CS342_2 1163-964 & $60-64$ & 4.26 & 9.6 & 1.17 & $0.266 * *$ & \\
\hline & & & 2 & 4 & 84 & CS190_2 1011-1172 & $82-86$ & 4.89 & 10.9 & -1.32 & $0.284 * *$ & \\
\hline & & & 3 & 4 & 72 & AD25_5 2420-2343 & $70-74$ & 7.38 & 16.5 & -2.29 & $0.434 * *$ & \\
\hline & & & 4 & 5 & 28 & AD185_5 2580-2701 & $26-30$ & 3.27 & 7.8 & 1.05 & $0.323 * *$ & \\
\hline & & & 5 & 6 & 4 & EF255_6 3116-3143 & $2 \_6$ & 3.67 & 8.4 & -0.89 & $0.250 * *$ & \\
\hline & & & 6 & 9 & 88 & BF138_9 4205-4203 & $86-90$ & 3.25 & 7.5 & -1.75 & $0.568 * *$ & \\
\hline & & & 7 & 8 & 44 & JK208_8 3856-3959 & $42-46$ & 3.7 & 8.4 & -7.28 & 0.96 & \\
\hline & & & 8 & 9 & 86 & BF137_9 4204-4205 & $84-88$ & 7.13 & 15.6 & -6.49 & $0.878 * *$ & 84.7 \\
\hline & & ST & 1 & 1 & 18 & SB466_1 456-453 & $16-20$ & 3.48 & 8.1 & 2.7 & $0.736 * *$ & \\
\hline & & & 2 & 2 & 52 & CS132_2 953-954 & $48-58$ & 3.27 & 7.5 & -1.9 & $0.531 * *$ & \\
\hline & & & 3 & 2 & 54 & CS133_2 954-955 & $48-58$ & 3.2 & 7.4 & -2.01 & $0.563 * *$ & \\
\hline & & & 4 & 2 & 90 & CS150_2 971-1177 & $88-92$ & 3.99 & 9.1 & -2.3 & $0.597 * *$ & \\
\hline & & & 5 & 3 & 30 & DB140_3 1564-1547 & $28-32$ & 3.97 & 4.49 & 2.68 & $0.550 * *$ & \\
\hline & & & 6 & 7 & 22 & GH87_7 3378-3376 & $20-24$ & 3.04 & 7.1 & -2.1 & $0.644 *$ & \\
\hline & & & 7 & 3 & 32 & DB143_3 1567-1568 & $30-34$ & 6.17 & 13.9 & 3.98 & 0.515 & \\
\hline & & & 8 & 4 & 46 & BC140_4 2240-2229 & $42-50$ & 3.64 & 8.5 & 2.98 & $0.868 * *$ & \\
\hline & & & 9 & 7 & 74 & GH108_7 3399-3420 & $72-76$ & 3.48 & 8.2 & -4.53 & $1.351 *$ & 74.29 \\
\hline & & WX & 1 & 3 & 36 & DB146_3 1570-1571 & $34-40$ & 5.26 & 11.9 & -0.797 & 0.069 & \\
\hline & & & 2 & 5 & 20 & AD290_5 2685-2683 & $18-22$ & 4.01 & 9.4 & -0.337 & 0.078 & \\
\hline & & & 3 & 7 & 52 & GH99_7 3390-3391 & $50-58$ & 5.43 & 12.3 & 0.922 & $0.219 * *$ & 33.6 \\
\hline & & VG & 1 & 3 & 58 & DB163_3 1587-1588 & $56-60$ & 3.03 & 6.9 & 0.142 & $0.040 * *$ & 6.9 \\
\hline & & TR & 1 & 3 & 70 & DB172_3 1596-1603 & $68-72$ & 3.16 & 7.3 & 2.171 & 0.660 & \\
\hline & & & 2 & 6 & 16 & EF184_6 3045-3161 & $12-18$ & 3.06 & 7.1 & -2.307 & $0.721 * *$ & \\
\hline & & & 3 & 9 & 72 & BF123_9 4190-4193 & $70-74$ & 7.22 & 16 & -24.470 & $3.946 * *$ & 30.4 \\
\hline & & GL & 1 & 2 & 104 & CS156_2 977-1188 & $102-106$ & 3.51 & 8.0 & -0.240 & $0.070 *$ & \\
\hline & & & 2 & 3 & 4 & DB40_3 1464-1463 & $2-6$ & 4.17 & 15.9 & 0.139 & $0.029 *$ & \\
\hline & & & 3 & 3 & 76 & DB169_3 1593-1592 & $74-82$ & 3.20 & 7.3 & 0.091 & 0.028 & \\
\hline & & & 4 & 6 & 60 & EF325_6 3186-3073 & $58-62$ & 5.62 & 12.5 & 0.874 & $0.196 * *$ & \\
\hline & & & 5 & 9 & 60 & BF112_9 4179-4191 & $58-62$ & 4.19 & 9.6 & -0.193 & $0.052 * *$ & 53.3 \\
\hline \multirow{11}{*}{ C. partellus } & \multirow[t]{11}{*}{ Kiboko } & $\mathrm{DH}$ & 1 & 2 & 116 & CS369_2 1190-1197 & $114-118$ & 3.62 & 8.6 & 3.32 & $0.916 * *$ & \\
\hline & & & 2 & 2 & 134 & CS389_2 1210-1041 & $132-136$ & 4.99 & 11.7 & -2.71 & $0.622 * *$ & \\
\hline & & & 3 & 6 & 56 & EF322_6 3183-3184 & $54-58$ & 3.49 & 8.3 & -3.17 & $0.762 *$ & \\
\hline & & & 4 & 9 & 106 & BF152_9 4219-4220 & $104-108$ & 3.13 & 12.6 & -8.46 & $.815 *$ & 41.2 \\
\hline & & LD & 1 & 2 & 56 & CS133_2 954-955 & $52-58$ & 3.84 & 8.7 & -3.07 & $0.758 *$ & \\
\hline & & & 2 & 2 & 132 & CS397_2 1218-1219 & $130-134$ & 3.78 & 8.6 & -3.06 & $0.804 * *$ & \\
\hline & & & 3 & 6 & 16 & EF184_6 3045-3161 & $14-18$ & 3.14 & 7.2 & 2.76 & $0.801 * *$ & 24.5 \\
\hline & & $\mathrm{EH}$ & 1 & 3 & 50 & DB153_3 1577-1580 & $42-52$ & 3.99 & 9.1 & 0.59 & $0.153 *$ & \\
\hline & & & 2 & 3 & 134 & DB208_3 1632-1635 & $130-136$ & 3.67 & 8.5 & -1.01 & $0.287 * *$ & \\
\hline & & & 3 & 4 & 40 & BC222_4 2322-2239 & $38-42$ & 3.12 & 7.2 & -0.89 & $0.255 *$ & \\
\hline & & & 4 & 5 & 16 & $\mathrm{~m} 05 / 015.62567-2709$ & $14-18$ & 3.6 & 8.4 & -8.04 & $2.229 * *$ & \\
\hline
\end{tabular}


TABle 12: Continued.

\begin{tabular}{|c|c|c|c|c|c|c|c|c|c|c|c|c|}
\hline $\begin{array}{l}\text { Pest } \\
\text { species }\end{array}$ & Site & Trait & QTL & Chr. & $\begin{array}{l}\text { Position } \\
(\mathrm{cM})\end{array}$ & $\begin{array}{c}\text { Marker and loci } \\
\text { interval }\end{array}$ & $\begin{array}{c}\text { Supp } \\
\text { interval }\end{array}$ & LOD & $R^{2}$ & $\begin{array}{l}\text { Additive } \\
\text { effects }\end{array}$ & SE & $\begin{array}{c}\operatorname{Adj} \sigma^{2} \\
\quad g\end{array}$ \\
\hline & & & 5 & 2 & 148 & CS414_2 1235-1083 & $146-150$ & 3.04 & 7.4 & 0.61 & 0.183 & \\
\hline & & & 6 & 6 & 4 & EF255_6 3116-3143 & $2 \_6$ & 3.21 & 7.6 & -0.55 & $0.172 * *$ & \\
\hline & & & 7 & 7 & 16 & GH66_7 3357-3367 & $14-18$ & 4.05 & 10.3 & -0.51 & $0.148 *$ & 58.5 \\
\hline & & ST & 1 & 3 & 42 & DB152_3 1576-1573 & $40-46$ & 5.08 & 11.4 & 2.64 & $0.391 *$ & \\
\hline & & & 2 & 7 & 24 & GH70_7 3361-3371 & $22-26$ & 3.4 & 7.8 & -1.83 & $0.471 *$ & \\
\hline & & & 3 & 7 & 90 & GH118_7 3409-3404 & $88-94$ & 3.99 & 9.5 & -3.56 & 0.837 & 28.7 \\
\hline & & WX & 1 & 2 & 154 & CS259_2 1080-1099 & $152-168$ & 3.88 & 13.5 & -0.631 & 0.126 & 13.5 \\
\hline & & VG & 1 & 2 & 122 & CS380_2 1201-1205 & $120-126$ & 3.84 & 8.7 & 0.216 & $0.055 * *$ & \\
\hline & & & 2 & 6 & 22 & EF303_6 3164-3158 & $20-24$ & 3.04 & 7.1 & 1.546 & $0.490 *$ & \\
\hline & & & 3 & 7 & 76 & GH108_7 3399-3420 & $74-78$ & 4.18 & 9.8 & -1.036 & $0.264 *$ & \\
\hline & & & 4 & 8 & 20 & JK281_8 3929-3930 & $18-22$ & 3.61 & 8.6 & -0.259 & $0.068 * *$ & \\
\hline & & & 5 & 8 & 20 & JK281_8 3929-3930 & $16-22$ & 3.58 & 8.7 & -0.279 & $0.073 * *$ & \\
\hline & & & 6 & 8 & 20 & JK281_8 3929-3930 & $16-22$ & 4.00 & 9.6 & -0.266 & $0.073 * *$ & 52.5 \\
\hline & & GL & 1 & 2 & 104 & CS156_2 977-1188 & $102-106$ & 3.51 & 8.0 & -0.240 & $0.070 *$ & \\
\hline & & & 2 & 3 & 4 & DB40_3 1464-1463 & $2-6$ & 4.17 & 15.9 & 0.139 & $0.029 *$ & \\
\hline & & & 3 & 3 & 76 & DB169_3 1593-1592 & $74-82$ & 3.20 & 7.3 & 0.091 & 0.028 & \\
\hline & & & 4 & 5 & 28 & AD185_5 2580-2701 & $26-30$ & 3.15 & 7.6 & -0.168 & 0.046 & \\
\hline & & & 5 & 6 & 60 & EF325_6 3186-3073 & $58-62$ & 5.62 & 12.5 & 0.874 & $0.052 * *$ & \\
\hline & & & 6 & 6 & 60 & EF325_6 3186-3073 & $58-62$ & 5.12 & 11.6 & 0.867 & $0.230 * *$ & \\
\hline & & & 7 & 6 & 60 & EF325_6 3186-3073 & $58-62$ & 3.19 & 7.5 & 0.838 & $0.223 * *$ & \\
\hline & & & 8 & 7 & 22 & GH87_7 3378-3376 & $18-24$ & 3.55 & 8.3 & 0.159 & $0.038 *$ & \\
\hline & & & 9 & 7 & 36 & GH90_7 3381-3382 & $30-40$ & 3.24 & 7.5 & -0.328 & $0.110 *$ & \\
\hline & & & 10 & 7 & 76 & GH108_7 3399-3420 & $74-78$ & 3.27 & 7.6 & -0.541 & $0.147 * *$ & \\
\hline & & & 11 & 9 & 48 & BF102_9 4169-4171 & $44-50$ & 4.08 & 9.4 & -0.287 & $0.083 *$ & \\
\hline & & & 12 & 9 & 60 & BF112_9 4179-4191 & $58-62$ & 4.19 & 9.6 & -0.193 & $0.052 * *$ & 112.8 \\
\hline
\end{tabular}

$\mathrm{QTL}=$ quantitative trait loci; $\mathrm{Chr}=$ chromosome; $\mathrm{cM}=$ centimorgan; Position=maximum peak in $\mathrm{cM}$, relative to the first locus on each chromosome; Supp interval=supportive interval; LOD=likelihood-ratio test statistic; Additive effect=regression coefficient of the QTL at the specific position from the multiple regression analysis. Positive additive effects indicate that the PB 15520-1 (resistant parent) allele increased the value of the trait; $\mathrm{SE}=$ standard error; $R^{2}$ $=$ coefficient of determination between the respective QTL and the phenotypic observations from the whole data set; Adj $\sigma^{2} g=$ adjusted genetic variance. * and $* *$ indicate that data are significant at the $\leq 0.05$ and $\leq 0.01$ probability levels, respectively; $\mathrm{DH}=$ deadheart damage; $\mathrm{LD}=$ leaf feeding damage; $\mathrm{EH}=$ exit holes; $\mathrm{ST}=$ =stem tunneling; $\mathrm{WX}=$ bloom waxiness; $\mathrm{VG}=$ seedling vigour; $\mathrm{TR}=$ trichome density; $\mathrm{GL}=$ leaf glossiness. Marker names in the table were coded for ease of analyses, and their full names are in the supplementary material (see).

additive gene action ranged from -20.68 to 12.95 . Four of the QTLs on chromosomes 1, 2, 4, and 9 (flanked by markers on markers SB691_1, CS259_2, BC149_4, and BF97_9) were from the susceptible parent, while the QTLs on chromosomes 2, 3, 8, and 9 (flanked by markers CS402_2, CS350_2, DB172_3, DB169_3, JK399_8, and BF106_9) came from the resistant parent (PB 15520) which contributed to less deadheart damage.

Seven QTLs for leaf feeding damage due to B. fusca at Kabete site were detected on markers on chromosomes 2, 3, 6, 8, and 10 (flanked by markers CS403_2, CS111_2, CS397_2, DB164_3, EF334_6, m08/014.9, and CPS158_10) (Table 12 ). These explained $1.3 \%$ of the phenotypic variation, with individual QTLs accounting for 7\% - 13\%. A simultaneous fit with all the seven QTLs based on cross validation explained $66.8 \%$ of the adjusted genetic variance. The addi- tive gene action ranged from -14.42 to 6.56 . Three of the QTLs on chromosomes 2 and 10 (flanked by markers CS111_2, CS397_2, and CPS158_10, respectively) came from the susceptible parent (ICSV 745). QTLs on markers on chromosomes 2, 3, 6, and 8 (flanked by markers CS403_2, DB164_3, EF334_6, and m08/014.9, respectively) came from the resistant parent (PB 15520-1) which contributed to less leaf feeding damage.

Eight QTLs for exit holes due to $B$. fusca at Kabete site were detected on chromosomes 2, 5, 6, 8, and 9 (flanked by markers CS342_2, CS190_2, AD25_5, AD185_5, EF255_6, JK208_8, BF138_9, and BF137_9) (Table 12). These explained $6.1 \%$ of the phenotypic variation, with individual QTLs accounting for 7.5\%-16.5\%. A simultaneous fit with all the eight QTLs based on cross validation explained $84.7 \%$ of the adjusted genetic variance. The additive gene 
action ranged from -7.28 to 1.17. Two of the QTLs on chromosomes 2 and 5 (flanked by markers CS342_2 and AD185_ 5 , respectively) came from the susceptible parent (ICSV 745). The rest of the six QTLs on chromosomes 2, 5, 6, 8, and 9 (flanked by markers CS190_2, AD25_5, EF255_6, JK208_8, BF138_9, and BF137_9) came from the resistant parent (PB 15520-1) which contributed to less exit hole damage.

Nine QTLs for stem tunneling damage due to B. fusca at Kabete site were on chromosomes 1, 2, 3, 4, and 7 (flanked by markers SB466_1, CS132_2, CS133_2, CS150_2, DB140_3, DB143_3, BC140_4, GH87_7, and GH108_7) (Table 12). These QTLs explained $0.16 \%$ of the phenotypic variation, with individual QTLs accounting for 7.1\% - 13.9\%. A simultaneous fit with all the nine QTLs based on cross validation explained $74.29 \%$ of the adjusted genetic variance. The additive gene action ranged from -4.53 to 3.98. Four of the QTLs on chromosomes 1, 3, and 4 (flanked by markers SB466_1, DB140_3, DB143_3, and BC140_4) came from the susceptible parent (ICSV 745). The other five QTLs on chromosomes 2 and 7 (flanked by markers CS132_2, CS133_2, CS150_2, GH87_7, and GH108_7) came from the resistant parent (PB 15520-1) which contributed to less stem tunneling damage.

Four QTLs for deadheart damage due to C. partellus at Kiboko site were detected on chromosomes 2, 6, and 9 (flanked by markers CS369_2, CS389_2, EF322_6, and BF152_9) (Table 12). These QTLs explained 2.7\% of the phenotypic variation with individual QTLs accounting for $8.3 \%-12.6 \%$. A simultaneous fit with all the four QTLs based on cross validation explained $41.2 \%$ of the adjusted genetic variance. The additive gene action ranged from -8.46 to 3.32 . One of the QTLs on chromosome 2 (flanked by marker CS369_2) came from the susceptible parent (ICSV 745), while the other three QTLs came from the resistant parent (PB 15520-1) which contributed to less deadheart damage.

Three QTLs for leaf feeding damage due to C. partellus at Kiboko site were detected on chromosomes 2 and 6 (flanked by markers CS133_2, CS397_2, and EF184_6) (Table 12). The markers explained $4.1 \%$ of the phenotypic variation with individual QTLs accounting for 7.2\% - 8.7\%. A simultaneous fit with all the three QTLs based on cross validation explained $24.5 \%$ of the adjusted genetic variance. The additive gene action ranged from -3.07 to 2.76. All the three QTLs came from the resistant parent (PB 15520-1) which contributed to reduce leaf feeding damage.

Seven QTLs for exit hole damage due to C. partellus at Kiboko site were detected on chromosomes 2, 3, 4, 5, 6, and 7 (flanked by markers CS414_2, DB153_3, DB208_3, BC222_4, m05/015.6, EF255_6, and GH66_7) (Table 12). The QTLs explained 1.4\% of the phenotypic variation with individual QTLs accounting for 7.2\% - 10.3\%. A simultaneous fit with all the seven QTLs based on cross validation explained $58.5 \%$ of the adjusted genetic variance. The additive gene action ranged from -8.04 to 0.61 . Two of the QTLs on chromosomes 2 and 3 (flanked by markers CS414_2 and DB153_3) came from the susceptible parent (ICSV 745). The other five QTLs came from the resistant parent (PB 15520-1), an indication of the transfer of the resistance genes to the progenies.
Three QTLs for stem tunneling damage due to C. partellus at Kiboko site were detected on chromosomes 3 and 7 (flanked by markers DB152_3, GH70_7, and GH118_7) (Table 12). These explained $0.29 \%$ of the phenotypic variation, with individual QTLs accounting for $7.8 \%-11.4 \%$. A simultaneous fit with all the three QTLs based on cross validation explained $28.7 \%$ of the adjusted genetic variance. The additive gene action ranged from -3.56 to 2.64. One of the QTLs on chromosome 3 flanked by marker DB152_3 came from the susceptible parent (ICSV 745), while the other two QTLs came from the resistant parent (PB 15520-1).

Colocalization of markers for some of the traits evaluated was detected on site analysis for B. fusca (at Embu and Kabete), and C. partellus (at Kiboko) (Table 12). For example, it was observed that the region flanked by markers (DB172_3, EF184_6, and BF123_9) on chromosomes 3, 6, and 9 conditioned trichome density, deadheart damage, and stem tunneling damage at Kabete. Marker DB169_3 on chromosome 3 conditioned leaf glossiness and deadheart damage at Kabete. Marker CS403_2 on chromosome 2 conditioned seedling vigour and leaf damage at Kabete and Embu, respectively. Marker AD323_5 on chromosome 5 conditioned resistance to deadheart formation at Embu as well as seedling vigour at Embu. Marker CS259_2 on chromosome 2 conditioned resistance to deadheart formation at Kabete as well as bloom waxiness in Kiboko. Marker GH108_7 on chromosome 7 conditioned resistance to seedling vigour at Kiboko as well as stem tunneling in Kabete. Marker AD323_5 on chromosome 5 conditioned resistance to seedling vigour and deadheart damage at Embu. Marker CS389_ 2 conditioned resistance to leaf damage and deadheart damage at Embu and Kiboko. Marker CS414_2 on chromosome 2 conditioned resistance to exit holes at Kiboko and leaf damage at Embu. Marker CS190_2 on chromosome 2 conditioned resistance to leaf feeding at Embu and exit holes at Kabete.

Joint analysis of B. fusca and C. partellus damage and morphological traits across the three sites is presented on Table 13. Four QTLs due to deadheart damage were detected chromosomes 4, 5, 8, and 10 (flanked by markers BC242-4, m05/023.7, JK399-8, and CPS160-10, respectively) (Table 13). These explained $2.3 \%$ of the phenotypic variation, with individual QTLs accounting for 7.5\% - 9\%. A simultaneous fit with all the four QTLs based on cross validation explained $24.8 \%$ of the adjusted genetic variance. The additive gene action ranged from 3.32 to 16.64 . One of the QTLs on chromosome 8 (flanked by marker JK399-8) came from the resistant parent (PB 15520-1), while the other three QTLs came from the susceptible parent (ICSV 745).

Six QTLs for leaf feeding damage were detected on markers on chromosomes $1,3,6,7$, and 8 (flanked by markers SB255-1, DB160-3, DB169-3, EF222-6, GH70-7, and JK290-8) Table 13). These explained $2.25 \%$ of the phenotypic variation, with individual QTLs accounting for 7.6\% $17.4 \%$. A simultaneous fit with all the six QTLs based on cross validation explained $56 \%$ of the adjusted genetic variance. The additive gene action ranged from -2.02 to 5.070. Two of the QTLs on chromosomes 3 and 7 (flanked by markers $D B 169-3$ and $G H 70-7$, respectively) came from the 
TABLE 13: Joint analyses for QTLs common for B. fusca and C. partellus damage and morphological traits from the RIL population derived from ICSV $745 \times$ PB 15520-1 sorghum.

\begin{tabular}{|c|c|c|c|c|c|c|c|c|c|c|}
\hline Trait & QTL & Chromosome & $\begin{array}{l}\text { Position } \\
\text { (cM) }\end{array}$ & $\begin{array}{c}\text { Marker and loci } \\
\text { interval }\end{array}$ & $\begin{array}{c}\text { Supp } \\
\text { interval }\end{array}$ & LOD & $R^{2}$ & $\begin{array}{l}\text { Additive } \\
\text { effects }\end{array}$ & SE & $\begin{array}{c}\operatorname{Adj} \sigma^{2} \\
g\end{array}$ \\
\hline \multirow{4}{*}{ Deadheart } & 1 & 4 & 74 & BC242-4 2342-2347 & $72-78$ & 3.81 & 9 & 16.6 & $1.587 *$ & \\
\hline & 2 & 5 & 24 & $\mathrm{~m} 05 / 023.7$ 2703-2679 & $22-26$ & 3.31 & 7.6 & 3.3 & $0.981 * *$ & 24.8 \\
\hline & 3 & 10 & 22 & CPS160-10 4619-4622 & $18-28$ & 3.16 & 8.2 & 5.4 & $1.336 *$ & \\
\hline & 4 & 8 & 40 & JK399-8 36-42 & $36-42$ & 3.41 & 7.8 & -9.5 & $2.758 *$ & \\
\hline \multirow{6}{*}{ Leaf damage } & 1 & 1 & 14 & SB255-1 245-224 & $12-16$ & 6.28 & 15.4 & 3.8 & $0.822 * *$ & \\
\hline & 2 & 3 & 54 & DB160-3 1584-1579 & $52-56$ & 7.88 & 17.4 & 5.1 & 0.657 & 56 \\
\hline & 3 & 3 & 74 & DB169-3 1593-1592 & $72-84$ & 3.48 & 8.1 & -2 & 0.646 & \\
\hline & 4 & 6 & 76 & EF222-6 3083-3203 & $72-78$ & 3.26 & 7.6 & 3.9 & 1.077 & \\
\hline & 5 & 8 & 48 & JK290-8 3938-3944 & $46-52$ & 3.24 & 7.6 & 2.2 & 0.705 & \\
\hline & 6 & 7 & 24 & GH70-7 3361-3371 & $22-26$ & 3.61 & 8.4 & -3.1 & $0.681 *$ & \\
\hline \multirow{5}{*}{ Exit holes } & 1 & 2 & 88 & CS195-2 1016-971 & $86-90$ & 3.94 & 9 & -0.5 & $0.142 * *$ & \\
\hline & 2 & 4 & 58 & BC149-4 2249-2250 & $56-60$ & 3.92 & 9 & -0.7 & $0.167 * *$ & 47.3 \\
\hline & 3 & 6 & 4 & EF255-6 3116-3143 & $2-6$ & 5.14 & 11.7 & -0.7 & $0.154 * *$ & \\
\hline & 4 & 6 & 26 & EF416-6 3277-3281 & $24-28$ & 4.64 & 10.5 & 3.2 & $0.743 * *$ & \\
\hline & 5 & 9 & 88 & BF138-9 4205-4203 & $84-90$ & 3 & 7 & 1.2 & $0.361 * *$ & \\
\hline \multirow{6}{*}{ Stem tunneling } & 1 & 1 & 18 & SB466_1 & $456-453$ & 3.55 & 8.2 & 1.982 & $0.523 *$ & \\
\hline & 2 & 2 & 16 & CS116-2 937-940 & $14-18$ & 5.18 & 11.8 & 1.6 & $0.365 * *$ & \\
\hline & 3 & 2 & 52 & CS132-2 953-954 & $46-56$ & 4.62 & 10.5 & -1.5 & $0.391 * *$ & \\
\hline & 4 & 3 & 20 & DB36_3 1460-1524 & $16-24$ & 3.34 & 10.1 & 4.4 & $0.618 * *$ & 65.5 \\
\hline & 5 & 4 & 46 & BC140_4 2240-2229 & $42-48$ & 6.57 & 14.7 & 3 & $0.631 * *$ & \\
\hline & 6 & 9 & 90 & BF140_9 4207-4210 & $88-92$ & 4.44 & 10.3 & -3.4 & 0.458 & \\
\hline \multirow{2}{*}{ Bloom waxiness } & 1 & 3 & 10 & DB39-3 1463-1461 & $2-12$ & 4.88 & 19.1 & 0.5 & $0.105 * *$ & 27.3 \\
\hline & 2 & 9 & 42 & BF97-9 4164-4168 & $40-46$ & 3.52 & 8.2 & 1.2 & 0.201 & \\
\hline \multirow{2}{*}{ Leaf glossiness } & 1 & 5 & 14 & AD443-5 2838-2676 & $12-16$ & 3.32 & 8.1 & -0.7 & $0.220 * *$ & 15.2 \\
\hline & 2 & 7 & 82 & GH120-7 3411-3410 & $80-84$ & 3.01 & 7.1 & -0.5 & $0.162 *$ & \\
\hline \multirow{4}{*}{$\begin{array}{l}\text { Trichome } \\
\text { density }\end{array}$} & 1 & 1 & 10 & SB259-1 249-245 & 8-12 & 3.03 & 7.7 & -6.6 & 1.752 & 40.5 \\
\hline & 2 & 2 & 122 & CS380-2 1201-1205 & $120-124$ & 4.66 & 10.4 & -4.1 & $1.007 * *$ & \\
\hline & 3 & 3 & 108 & DB390-3 1814-1619 & $102-110$ & 3.19 & 7.3 & 4.6 & $1.428 *$ & \\
\hline & 4 & 6 & 10 & EF154-6 3015-3153 & 8-12 & 6.90 & 15.0 & -7.8 & $1.435 *$ & \\
\hline \multirow{6}{*}{ Leaf toughness } & 1 & 2 & 56 & CS133-2 954-955 & $54-58$ & 3.01 & 7.1 & 0.01 & $0.006 *$ & 41.1 \\
\hline & 2 & 2 & 138 & CS402-2 1223-1224 & $136-140$ & 3.23 & 7.7 & 0.03 & 0.011 & \\
\hline & 3 & 4 & 24 & BC131-4 2231-2232 & $22-26$ & 3.51 & 8.8 & -0.04 & $0.012 * *$ & \\
\hline & 4 & 6 & 48 & EF204-6 3065-3009 & $46-50$ & 3.82 & 8.9 & 0.1 & $0.029 *$ & \\
\hline & 5 & 9 & 72 & BF123-9 4190-4193 & $70-74$ & 3.67 & 8.6 & -0.1 & $0.025 *$ & \\
\hline & 6 & 10 & 64 & $\mathrm{~m} 10 / 062.54638-4636$ & $60-66$ & 3.22 & 10.6 & 0.1 & $0.011 * *$ & \\
\hline \multirow{2}{*}{ Seedling vigour } & 1 & 8 & 12 & JK152-8 3800-3809 & $8-16$ & 3.05 & 8.7 & 0.3 & $0.099 * *$ & 19.5 \\
\hline & 2 & 9 & 20 & BF84-9 4151-4149 & $18-22$ & 4.59 & 10.8 & -0.9 & 0.076 & \\
\hline
\end{tabular}

QTL=quantitative trait loci; $\mathrm{cM}=$ centimorgan; Supp=supportive interval; $\mathrm{LOD}=$ likelihood-ratio test statistic; Position=maximum peak in $\mathrm{cM}$, relative to the first locus on each chromosome; Additive effect=regression coefficient of the QTL at the specific position from the multiple regression analysis. Positive additive effects indicate that the PB 15520-1 (resistant parent) allele increased the value of the trait; $\mathrm{SE}=$ standard error; $R^{2}=$ coefficient of determination between the respective QTL and the phenotypic observations from the whole data set; Adj $\sigma^{2} g=$ adjusted genetic variance. Here, marker names were coded for ease of analyses, and their full names are in the supplementary material (see). 
resistant parent (PB 15520-1) that contributed to reduce leaf feeding damage, while the other four QTLs came from the susceptible parent (ICSV 745).

Five QTLs for exit hole damage were detected on chromosomes 2, 4, 6, and 9 (flanked by markers CS195-2, BC149-4, EF255-6, EF416-6, and BF138-9) (Table 13). These explained $5.37 \%$ of the phenotypic variation, with individual QTLs accounting for 7\% - 11.7\%. A simultaneous fit with all the five QTLs based on cross validation explained $47.3 \%$ of the adjusted genetic variance. The additive gene action ranged from -0.7 to 3.2. Three of the QTLs on chromosomes 2, 4, and 6 (flanked by markers CS195-2, BC149-4, and EF255-6, respectively) came from the resistant parent (PB 15520-1), while the other two QTLs came from the susceptible parent (ICSV 745).

Six QTLs for stem tunneling damage were detected on chromosomes 1, 2, 3, 4, and 9 (flanked by markers SB466_ 1, CS116-2, CS132-2, DB36_3, BC140_4, and BF140_9) (Table 13). These explained $5.37 \%$ of the phenotypic variation, with individual QTLs accounting for 10.1\%-14.7\%. A simultaneous fit with all the five QTLs based on cross validation explained $65.5 \%$ of the adjusted genetic variance. The additive gene action ranged from -3.4 to 4.4 . Two of the QTLs on chromosomes 2 and 9 (flanked by markers CS1322 and BF140_9, respectively) came from the resistant parent (PB 15520-1), while the other four QTLs came from the susceptible parent (ICSV 745). The analyses further revealed that marker CS132-2 was colocalised for leaf toughness and stem tunneling traits on QTL 1 and 2, respectively.

\section{Discussion}

Heritability is used to predict response to selection and to help plant breeders know if it is more efficient to improve traits of economic importance through selection [31]. Heritability estimates thus explain the level to which genes control expression of the trait of interest. Heritability estimates for deadheart formation, leaf feeding damage, exit holes, stem tunneling, bloom waxiness, and seedling vigour tested for B. fusca at Embu and Kabete were low to high and ranged between 0.21 and 0.65 . On the other hand, heritability estimates for the same aforementioned traits evaluated for $C$. partellus at Kiboko were low and ranged between 0.15 and 0.32 . This observation suggested that genetic gain may not be realized in selection for some of the traits evaluated for the two borer species in the three sites. These traits that had low heritabilities are as follows: leaf feeding damage at Kabete and Kiboko; deadheart formation, bloom waxiness, and seedling vigour at Kiboko; and exit holes at all the three sites. Therefore, there is a need to consider other alternatives such as DNA marker technology to fix the desired genes. This observation is supported by other researchers. For example, Oloyede-Kamiyo et al. [31] worked on variability for resistance to the pink stem borer (Sesamia calamistis Hampson) and the sugarcane borer (Eldana saccharina Walker) in two tropical maize populations and observed that narrow-sense heritability was low to moderate and ranged from $1.45 \%$ for leaf feeding to $40.6 \%$ for stalk breakage.
Path coefficient analyses revealed that leaf feeding, deadheart, exit holes, and stem tunneling had a direct negative effect on grain yield. This observation suggested that either of the damage traits could lead to direct grain yield loss. Singh et al. [6] observed that direct effects of stem tunneling by $C$. partellus on grain yield loss were greater than leaf feeding and deadhearts in sorghum. However, Starks and Doggett [32] reported that leaf feeding damage by C. partellus in sorghum is a weak pointer of grain yield as production of new fresh leaves compensate for the leaf damage. Sandoya et al. [33] reported that improvement of maize stem tunneling resistance to the Mediterranean corn borer (Sesamia nonagrioides Lef) and the European corn borer (Ostrinia nubilalis Hbn) led to increased grain yield. The significant positive correlations observed between leaf damage and deadheart, and between stem tunneling and exit holes, implied that there is a direct relationship between the two traits, respectively, and either of the traits can be used to predict the other in the sorghum population studied. Generally, tall vigorous plants with bloom waxiness produced longer panicle length and high yield with less stem damage. There was a negative relationship between stem tunneling and bloom waxiness and between seedling vigour and deadheart formation implying that sorghum can be bred with either of the morphological traits for reduced damage with high grain yield to the two stem borers.

Colocalization of the markers for some of the traits evaluated was detected on site analysis for B. fusca (at Embu and Kabete) and C. partellus (at Kiboko). For example, it was observed that the region (flanked by markers $D B 172$ 3, EF184_6, and BF123_9) on chromosomes 3, 6, and 9, respectively, conditioned trichome density, deadheart damage, and stem tunneling damage at Kabete for B. fusca. This observation implies that the aforementioned traits can be improved by using the same linked markers. Marker DB169_3 on chromosome 3 conditioned leaf glossiness and deadheart damage at Kabete implying that both traits can be improved by using the same linked marker for B. fusca. Marker CS403_2 on chromosome 2 conditioned seedling vigour and leaf damage for B. fusca at Kabete and C. partellus at Embu, respectively, implying that both traits can be improved by using the same linked marker. Marker AD323_5 on chromosome 5 conditioned resistance to deadheart formation as well as seedling vigour at Embu (for B. fusca) suggesting that both traits can be improved by using the same linked marker. Marker CS259_2 on chromosome 2 conditioned resistance to deadheart formation at Kabete (for B. fusca) as well as bloom waxiness in Kiboko (for C. partellus) implying that the two traits can be improved by using the same linked marker. Marker GH108_7 on chromosome 7 conditioned resistance to seedling vigour at Kiboko (for C. partellus) as well as stem tunneling in Kabete (for B. fusca) implying that both traits can be improved by using the same linked marker. Marker AD323_5 on chromosome 5 conditioned resistance to seedling vigour and deadheart damage at Embu (for B. fusca) implying that both traits can be improved by using the same linked marker. Marker CS389_2 conditioned resistance to leaf damage and deadheart damage at Embu (for B. fusca) and Kiboko (for C. partellus) implying that both traits can 
be improved by using the same linked marker. Marker CS414_2 on chromosome 2 conditioned resistance to exit holes at Kiboko (for C. partellus) and leaf damage at Embu (for B. fusca) implying that both traits can be improved by using the same linked marker. Marker CS190_2 on chromosome 2 conditioned resistance to leaf feeding at Embu and exit holes at Kabete implying that both traits can be improved by using the same linked marker for B. fusca.

This study identified and mapped genomic regions conditioning dual resistance to B. fusca and C. partellus in sorghum. The study utilized a large number of RILs and highdensity evenly spaced genetic markers scored to ensure high power and precision in QTL mapping as described by Bekele et al. [34]. A five-fold cross validation analysis was run in this study as described by Gowda et al. [30] to confirm the frequency of QTL detection that gave an estimation of the precision of QTL localization. Identification of QTLs that influence dual resistance to B. fusca and C. partellus would increase the efficiency of selection and breeding for resistance of these two cereal stem borer species. Majority of the identified loci were highly significant, and they accounted for a substantial amount of phenotypic variation for B. fusca and C. partellus. This implied that fixing these traits (leaf feeding, deadheart formation, exit holes, and stem tunneling damages) would lead to the development of resistant cultivars and thus improve food security since the losses to stem borers will be lowered. A number of reports on linkage and QTL mapping for borer resistance traits have been published in maize [35-37]. QTL mapping for C. partellus resistance using the same sorghum mapping population utilized in this study is reported by Vinayan [20]. QTLs governing more than one resistance trait (pleiotropic QTLs) were identified in the present study. For example, it was observed that markers DB172_3, EF184_6, and BF123_9 on chromosomes 3,6 , and 9 conditioned trichome density, deadheart damage, and stem tunneling damage at Kabete implying that all these traits can be improved using the same linked markers. Pleotropic QTLs conditioning resistance to borers have been reported in the maize population [38-40].

Chromosome 1 has been associated with multiple resistance to lepidopteran insect pests, mainly, the European corn borer (Ostrinia nubilalis (Hubner)), the southwestern corn borer (Diatrea grandiosella (Dyar)), and the sugarcane borer (Diatraea saccharalis (Fabricius)), and resistance to the maize weevil [41]. Chromosome 4 has been reported to condition resistance to stem tunneling in the tropical maize population against the corn borer $[42,43]$. Chromosomes 1, 3, and 8 have been associated with resistance to Mediterranean corn borer Sesamia nonagrioides stem tunneling using EP39 $\times$ EP42 maize RILs [44]. Chromosomes 1, 2, 6, and 7 in sorghum have also been reported to regulate resistance to deadheart formation against sorghum shoot fly [45]. Joint analyses across the two species of stem borers and the three sites revealed that 4 QTLs conditioned deadheart damage (chr. 4, 5, 10, and 8) and trichome density (chr. 1, 2, 4, and 6); 6 QTLs conditioned leaf feeding damage (chr. 1, 3, 6, 7, and 8), stem tunneling damages (chr. 1, 2, 3, 4, and 9), and leaf toughness (chr. 2, 4, 6, 9, and 10); 5 QTLs conditioned exit holes (chr. 2, 4, 6, and 9); and 2 QTLs conditioned bloom waxiness (chr. 3, and 9), leaf glossiness (chr. 5, and 7), and seedling vigour (chr. 8, and 9). Genomic regions governing trichome density detected on sorghum chromosomes 2 , and 6 in this study have not been reported. QTLs identified for trichome density on chromosomes 1 and 3 in the joint analyses in the current study have also been reported in sorghum against shoot fly (Atherigona soccata Rond) [8, 45, 46]. Foerster et al. [47] reported that chromosome 9 conditioned bloom waxiness in maize. Aruna et al. [45] reported that chromosome 9 controlled seedling vigour in sorghum against shoot fly. Joint analyses further revealed that marker CS132-2 colocalised for leaf toughness and stem tunneling on QTLs 1 and 2 , respectively, implying that both traits can be improved with the help of the same linked marker.

\section{Conclusion and Recommendation}

This study identified and mapped genomic regions that conditioned expression of dual resistance to B. fusca and C. partellus in sorghum. QTLs identified in this study can be used in marker-assisted selection in the development of B. fuscaand C. partellus-resistant sorghum cultivars. Marker CS1322 colocalised for leaf toughness and stem tunneling on QTLs 1 and 2, respectively; thus, both traits can be improved for $B$. fusca and $C$. partellus with the help of the same linked marker. There is a need for further studies to identify gene(s) underlying the mapped QTLs.

\section{Data Availability}

Some of the data used to support the findings of this study are included in the article. Additional data are available from the corresponding author upon request.

\section{Conflicts of Interest}

The authors declare that there is no conflict of interest regarding the publication of this paper.

\section{Acknowledgments}

Financial support was obtained from Regional Universities Forum for Capacity Building in Agriculture (RUFORUM), Carnegie Corporation of New York, USA and the Harnessing Opportunities for Productivity Enhancement (HOPE) of Sorghum and Millets in Sub-Saharan Africa and South Asia Project funded by the Bill and Melinda Gates Foundation implemented by ICRISAT.

\section{Supplementary Materials}

Table 14 Coded markers and their names. (Supplementary Materials)

\section{References}

[1] K. M. Iskakova, B. B. Anapiyayev, E. B. Beisenbek, and A. S. Omarova, "Study of Sorghum bicolor L. for bioethanol production in the conditions of the south-east of Kazakhstan," in 
Plant Genetics, Genomics, Bioinformatics, and Biotechnology (PlantGen2019), June 2019Novosibirsk.

[2] Z. M. A. Bundhoo and D. Surroop, "Evaluation of the potential of bio-methane production from field-based crop residues in Africa," Renewable and Sustainable Energy Reviews, vol. 115, article 109357, 2019.

[3] R. Mutamiswa, F. Chidawanyika, and C. Nyamukondiwa, "Dominance of spotted stemborer Chilo partellus Swinhoe (Lepidoptera: Crambidae) over indigenous stemborer species in Africa's changing climates: ecological and thermal biology," Perspectives, vol. 2100, pp. 344-356, 2017.

[4] H. GrooteDe, "Maize yield losses from stemborers in Kenya," Insect Science and Its Applications, vol. 22, no. 2, pp. 89-96, 2002.

[5] P. G. Padmaja, Chapter 4-Insect Pest Resistance in Sorghum, Academic Press, 2016.

[6] B. U. Singh, H. C. Sharma, and K. V. Rao, "Mechanisms and genetic diversity for host plant resistance to spotted stem borer, Chilo partellus in sorghum, sorghum bicolor," Journal of Applied Entomology, vol. 136, no. 5, pp. 386400, 2012.

[7] P. W. Muturi, M. Mgonja, and P. Rubaihayo, "Identification of new sorghum genotypes resistant to the African and spotted stemborers," International Journal of Tropical Insect Science, vol. 34, no. 4, pp. 260-268, 2014.

[8] D. B. Apotikar, D. Venkateswarlu, R. B. Ghorade, R. M. Wadaskar, J. V. Patil, and P. L. Kulwal, "Mapping of shoot fly tolerance loci in sorghum using SSR markers," Journal of Genetics, vol. 90, no. 1, pp. 59-66, 2011.

[9] D. J. Bergvinson, R. I. Hamilton, and J. T. Arnason, "Leaf profile of maize resistance factors to European corn borer, Ostrinia nubilalis," Journal of Chemical Ecology, vol. 21, no. 3, pp. 343-354, 1995.

[10] F. Franeta, S. Mikić, Ž. Milovac, B. Mitrović, D. Inđić, and S. Vuković, "Maize defence mechanisms against the European corn borer, Ostrinia nubilalis Hübner (Lepidoptera: Crambidae)," International Journal of Pest Management, vol. 65, no. 1, pp. 23-32, 2019.

[11] O. Ibraheem, R. O. Adigun, and I. T. Olatunji, "Omics technologies in unraveling plant stress responses; using sorghum as a model crop, how far have we gone?," Vegetos, vol. 31, no. 2, pp. 1-18, 2018.

[12] Y. Li, X. Li, C. Ma, C. T. Hash, H. C. Sharma, and R. T. Folkertsma, "Airiti Library," in 13th International Biotechnology Symposium and Exhibition, pp. 1-7, Airiti Library, Taiwan, 2015.

[13] Y. Xu, P. Li, Z. Yang, and C. Xu, "Genetic mapping of quantitative trait loci in crops," The Crop Journal, vol. 5, no. 2, pp. 175-184, 2017.

[14] R. E. Boyles, B. K. Pfeiffer, E. A. Cooper et al., "Quantitative trait loci mapping of agronomic and yield traits in two grain sorghum biparental families," Crop Science, vol. 57, no. 5, pp. 2443-2456, 2017.

[15] E. S. Mace and D. R. Jordan, "Location of major effect genes in sorghum (Sorghum bicolor (L.) Moench)," Theoretical and Applied Genetics, vol. 121, no. 7, pp. 1339-1356, 2010.

[16] J. Ott, J. Wang, and S. M. Leal, "Genetic linkage analysis in the age of whole-genome sequencing," Nature Reviews Genetics, vol. 16, no. 5, pp. 275-284, 2015.

[17] S. Kumar, T. W. Banks, and S. Cloutier, "SNP discovery through next-generation sequencing and its applications,"
International Journal of Plant Genomics, vol. 2012, Article ID 831460, 15 pages, 2012.

[18] R. J. Elshire, J. C. Glaubitz, Q. Sun et al., "A robust, simple genotyping-by-sequencing (GBS) approach for high diversity species," PLoS One, vol. 6, no. 5, pp. 1-10, 2011.

[19] J. C. Glaubitz, T. M. Casstevens, F. Lu et al., "TASSEL-GBS: a high capacity genotyping by sequencing analysis pipeline," PLoS One, vol. 9, no. 2, 2014.

[20] M. T. Vinayan, Genetic architecture of spotted stem borer resistance in sorghum as inferred from QTL mapping and synteny with the maize genome. Thesis submitted in partial fulfillment of the requirement for the degree of doctor of philosophy (agriculture) in plant bree, Tamil Nadu Agricultural University, 2010.

[21] B. U. Singh, K. V. Rao, and H. C. Sharma, "Comparison of selection indices to identify sorghum genotypes resistant to the spotted stemborer Chilo partellus (Lepidoptera: Noctuidae)," International Journal of Tropical Insect Science, vol. 31, no. 1-2, pp. 38-51, 2011.

[22] V. K. Kumar, K. D. Reddy, and H. C. Sharma, Expression of Antixenosis and Antibiosis Components of Resistance to Spotted Stem Borer Chilo partellus in Sorghum under Greenhouse Conditions, Geo J, 2007.

[23] H. Shimelis and R. Shiringani, "Variance components and heritabilities of yield and agronomic traits among cowpea genotypes," Euphytica, vol. 176, no. 3, pp. 383-389, 2010.

[24] A. Hallauer and J. Miranda, Quantitative Genetics in Maize Breeding, Iowa State University Press, Ames, 1981.

[25] G. D. Garson, Testing Statistical Assumptions: Blue Book Series, Statistical Associate Publishing, Asheboro, 2012.

[26] J. B. Holland, "Estimating genotypic correlations and their standard errors using multivariate restricted maximum likelihood estimation with SAS Proc MIXED," Crop Science, vol. 46, no. 2, pp. 642-654, 2006.

[27] E. S. Mace, H. K. Buhariwalla, and J. H. Crouch, "A highthroughput DNA extraction protocol for tropical molecular breeding programs," Plant Molecular Biology Reporter, vol. 21, no. 4, pp. 459-460, 2003.

[28] J. W. OoijenVan, “JoinMap $4{ }^{\circledR}, ” 2006$, Software for the calculation of genetic linkage maps in experimental populations, Wageningen.

[29] H. F. Utz, Introduction to PLABQTL, Population (English Edition), 1995.

[30] M. Gowda, B. Das, D. Makumbi et al., "Genome-wide association and genomic prediction of resistance to maize lethal necrosis disease in tropical maize germplasm," Theoretical and Applied Genetics, vol. 128, no. 10, pp. 1957-1968, 2015.

[31] Q. Oloyede-Kamiyo, S. O. Ajala, and M. O. Akoroda, "Expected responses to selection for resistance to the pink stem borer (Sesamia calamistis Hampson) and the sugarcane borer (Eldana saccharina Walker) in two maize populations," Maydica, vol. 57, no. 2, pp. 121-128, 2012.

[32] K. J. Starks and H. Doggett, "Resistance to a spotted stem borer in sorghum and Maize123," Journal of Economic Entomology, vol. 63, no. 6, pp. 1790-1795, 1970.

[33] G. Sandoya, A. Butrón, R. Santiago, A. Alvarez, and R. A. Malvar, "Indirect response to selection for improving resistance to the Mediterranean corn borer (Sesamia nonagrioides Lef) in maize," Euphytica, vol. 176, no. 2, pp. 231-237, 2010.

[34] W. A. Bekele, S. Wieckhorst, W. Friedt, and R. J. Snowdon, "High-throughput genomics in sorghum: from whole- 
genome resequencing to a SNP screening array," Plant Biotechnology Journal, vol. 11, no. 9, pp. 1112-1125, 2013.

[35] J. C. Jiménez-Galindo, B. Ordás, A. Butrón, L. F. Samayoa, and R. A. Malvar, "QTL mapping for yield and resistance against Mediterranean corn borer in maize," Frontiers in Plant Science, vol. 8, pp. 2-11, 2017.

[36] L. F. Samayoa, R. A. Malvar, M. D. McMullen, and A. Butrón, "Identification of QTL for resistance to Mediterranean corn borer in a maize tropical line to improve temperate germplasm," BMC Plant Biology, vol. 15, no. 1, 2015.

[37] E. D. Womack, M. L. Warburton, and W. P. Williams, "Mapping of quantitative trait loci for resistance to fall armyworm and southwestern corn borer leaf-feeding damage in maize," Crop Science, vol. 58, no. 2, pp. 529-539, 2018.

[38] M. D. Krakowsky, M. Lee, and J. B. Holland, "Genotypic correlation and multivariate QTL analyses for cell wall components and resistance to stalk tunneling by the European corn borer in maize," Crop Science, vol. 47, no. 2, pp. 485-488, 2007.

[39] B. Ordas, R. A. Malvar, R. Santiago, G. Sandoya, M. C. Romay, and A. Butron, "Mapping of QTL for resistance to the Mediterranean corn borer attack using the intermated B73 $\times$ Mo17 (IBM) population of maize," Theoretical and Applied Genetics, vol. 119, no. 8, pp. 1451-1459, 2009.

[40] L. F. Samayoa, R. A. Malvar, B. A. Olukolu, J. B. Holland, and A. Butrón, "Genome-wide association study reveals a set of genes associated with resistance to the Mediterranean corn borer (Sesamia Nonagrioides L.) in a maize diversity panel," BMC Plant Biology, vol. 15, no. 1, p. 35, 2015.

[41] S. García-Lara, M. M. Khairallah, M. Vargas, and D. J. Bergvinson, "Mapping of QTL associated with maize weevil resistance in tropical maize," Crop Science, vol. 49, no. 1, pp. 139149, 2009.

[42] A. Butrón, M. C. Romay, J. Peña-Asín, A. Alvarez, and R. A. Malvar, "Genetic relationship between maize resistance to corn borer attack and yield," Crop Science, vol. 52, no. 3, pp. 1176-1180, 2012.

[43] X. LI, K.-1. HE, Z.-y. WANG, and S.-x. BAI, "Quantitative trait loci for Asian corn borer resistance in maize population $\mathrm{Mc}$ $37 \times$ Zi330," Agricultural Sciences in China, vol. 9, no. 1, pp. 77-84, 2010.

[44] B. Ordas, R. A. Malvar, R. Santiago, and A. Butron, "QTL mapping for Mediterranean corn borer resistance in European flint germplasm using recombinant inbred lines," BMC Genomics, vol. 11, no. 1, p. 174, 2010.

[45] C. Aruna, V. R. Bhagwat, R. Madhusudhana et al., "Identification and validation of genomic regions that affect shoot fly resistance in sorghum [Sorghum bicolor (L.) Moench]," Theoretical and Applied Genetics, vol. 122, no. 8, pp. 1617-1630, 2011.

[46] K. Satish, G. Srinivas, R. Madhusudhana et al., "Identification of quantitative trait loci for resistance to shoot fly in sorghum [Sorghum bicolor (L.) Moench]," Theoretical and Applied Genetics, vol. 119, no. 8, pp. 1425-1439, 2009.

[47] J. M. Foerster, T. Beissinger, N. de Leon, and S. Kaeppler, "Large effect QTL explain natural phenotypic variation for the developmental timing of vegetative phase change in maize (Zea mays L.)," Theoretical and Applied Genetics, vol. 128, no. 3, pp. 529-538, 2015. 